\title{
The Redemptive Potential of the Street. A Multi-angular Analysis of Dubai's Pedestrian Infrastructure
}

\author{
Lamia Abdelfattah, Filippo Bazzoni, Rawad Choubassi \\ Systematica srl, Italy \\ l.abdelfattah@systematica.net | f.bazzoni@systematica.net | r.choubassi@systematica.net
}

\begin{abstract}
Much has been written on the fast-paced development of Dubai as a city and the favouring of car-oriented streets in the approach to road building. This paper offers a reading of the city using forward-driven technological approaches in urban and transport planning to derive patterns and insights into areas of critical concern for intervention. The approach stems from the idea of incremental retrofitting as opposed to toppling over the current infrastructure. It is conceived as a way to significantly enhance the walkability and viability of Dubai's streets for its residents using minimal resources, while drastically enhancing their ability to utilize public space. The article revolves around a collection of mobility studies focused on the conditions of the street. In full, the extensive research traces the functional structure of 36 streets within the city, offering various insights into their potential to deliver better walkable environments. Mobility studies included in this report include field surveys and progressive applied simulation methods. In full, they offer taxonomic categorizations of Dubai's streets as well as possible concerted and planned retrofitting strategies to encourage safe and comfortable walking experiences. This paper focuses on how the interplay of various interdependent components of urban infrastructure creates the conditions for Dubai's street space to respond to walkability needs. Building on international practice and the latest disciplinary tools, this paper delves into the physical characteristics of Dubai's streets and interrogates some of the critical areas whereby minimal intervention is perceived to have a huge impact on spatiotemporal urban quality. In effect, the study highlights avenues for activating Dubai's most overlooked latent public spaces: its streets.
\end{abstract}

Keywords: walkability, walkability metrics, digital mapping tools, retrofitting strategies, Covid-19

To cite this article:

Abdelfattah, L., Bazzoni, F. and Choubassi, R. (202I) The Redemptive Potential of the Street. A Multi-angular Analysis of Dubai's Pedestrian Infrastructure, The Journal of Public Space, 6(I), 67-94. DOI: $10.32891 /$ jps.v6il.I326

This article has been double blind peer reviewed and accepted for publication in The Journal of Public Space. (c) (P) This work is licensed under a Creative Commons Attribution - Non Commercial 4.0 International License https://creativecommons.org/licenses/by-nc/4.0/ 
The Redemptive Potential of the Street.

\section{Introduction}

Dubbed as the fastest growing city on Earth in academic literature and the media alike, Dubai has received much attention over the past few decades for its unprecedented expansion rate (figure I). Fuelled by the desire to create a global image and supported by a booming economy and a strategic location on the Persian Gulf, the city experienced a blowout in terms of land coverage, expanding by 17 times its area between 1975 and 2015 (Elessawy 2017). However, as many researchers have duly noted, this rapid expansion was disproportionately focused on built-up development in comparison to public space design (Elsheshtawy 2008; Mushtaha et al. 2018). As originally coined by Yasser Elsheshtawy, Dubai the 'urban spectacle' was partly conceived as a theatricalized space with the main focus being its impressive starchitecture (Elsheshtawy 2010; cited in Montagne 2012). As explained by Mushtaha and others, Dubai's articulation of public spaces was lost in the shadows of its skyscrapers and mega infrastructure; whatever little space exists has likely been appropriated by residents to fit their functional and recreational needs (Mushtaha et al. 2018).
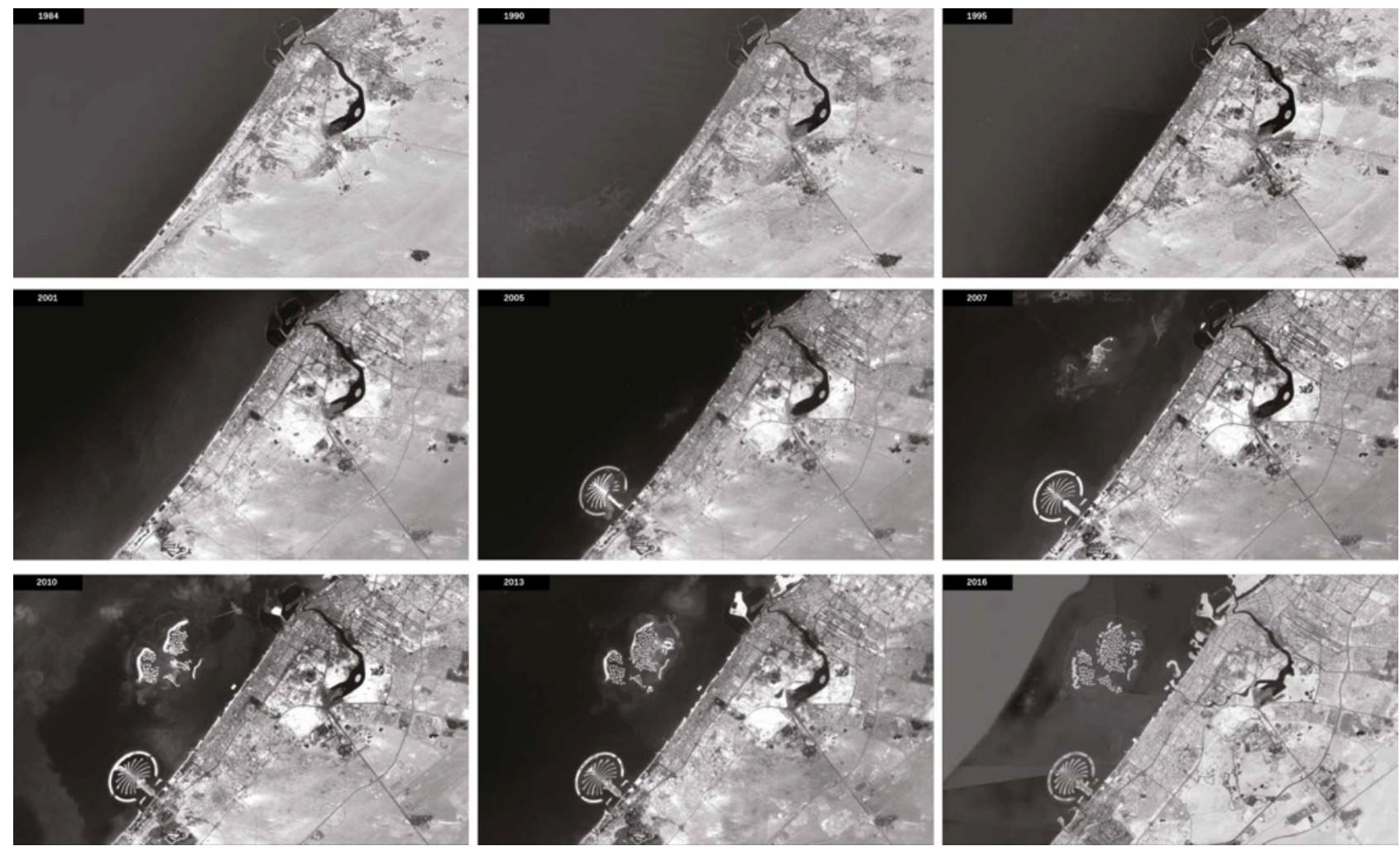

Figure I. Dubai's urban growth: a time-lapse 1984-2016 - property of Systematica srl

Today, master-planned communities and private developments by and large offer the most thoughtful open-air 'public spaces' to be enjoyed by their designated communities. These spaces, however, come at a financial cost to users and are subject to private laws of the estate developer (Chidiac 2020). Dubai is often envisioned as an archipelago of master-planned developments where recent focus on 'public' spaces is given to those spaces designed therein, with little attention given to publicly provided open space to be enjoyed by citizens at large. In a 2019 interview for Systematica, OMA director, partner 
and MENA regional project manager lyad Alsaka stated that "hasty development that took place in late 90 's and early 2000 , mainly led by semi government developers, and in complete absence of the city as a regulatory body, led to absence of public space and disconnection between 'islands' of the city." (Alsaka 2019).

This paper aims to direct the focus from the 'islands' of the city to the vast leftover space designed to connect these islands and the city in-between. According to the Dubai government, as of 2019 Dubai has close to 18,000 kilometres of road length across the city, up from 10,800 kilometres in 2009 - increasing by two thirds, or $66 \%$, in 10 years (Dubai Statistics Center 2009, 2019). Many of these roads and streets, however, are not adequately equipped to support safe and comfortable pedestrian movement. In other words, they suffer from low walkability. Put simply, walkability is a measure of how friendly a certain area is to walking. It falls under the broader paradigm of sustainable urban development maintaining evidence of its various health, environmental and economic benefits to a city (Speck 2013). Like many global cities, the way Dubai's mobility infrastructure is designed is centred around the movement of the car. Unsurprisingly, this planning approach has hurt the city in the long run as the infrastructure struggles to encompass its three-million-strong population. As a result, getting around the city is currently facilitated through six-lane highways, flyover junctions, overhead transit rail and a ground tram line that often act as an urban divider and contribute to a negative physical environment for those keen to travel on foot. In many countries to date, the only measure used to indicate an area's walkability is crash data. However, various progressive measures of walkability today extend beyond issues of pedestrian safety to include indices for comfort and enjoyment, underscoring the complexity of experiential factors in determining whether a certain street segment offers an inviting walkable environment for pedestrians. Some of these measures will be discussed herein and applied to Dubai to analyse its street infrastructure. It is important to also highlight the fact that walkability reinforces other space-efficient modes of travel such as cycling and micro-mobility -which tend to require the same physical conditions as walking- and public transport, since walking is essentially a part of any public transport or multi-modal trip.

\section{Methodology}

The studies presented in this paper were selected from a broad body of research examining the characteristics of Dubai's street networks, which was carried out by Systematica over the course of two years. The original body of work traces the organizational structure of streets across Dubai (figure 2) via two main strands of quantitative methods: (i) applied mapping methods using progressive and robust mobility analytical tools and (ii) site survey and direct observation, which constructively took place in the summer of 2017 (June-August). GIS programs used in the analytical process relied on models such as the Pedestrian Level of Service (PLOS), data from the patented system, Walk Score, network theories such as Space Syntax and CUBE software by Citilabs. This combination of mapping and direct observation provided a framework for reading and understanding the city with the ultimate purpose of strategizing and prioritizing retrofitting actions.

The research area for site survey and direct observation was focused on Dubai's highdensity city core, spanning from the Dubai Marina to Dubai Creek along the coast, and 
extending about $6 \mathrm{~km}$ inward towards the large Al-Khail road infrastructure. An inventory of 36 streets was drawn up for detailed survey and documentation, serving as the basis of the observational studies. In contrast, the study area for applied methods varied: it followed a global approach for Walk Score and Space Syntax analyses (extended across the city of Dubai) and followed a local approach for PLOS and pedestrian simulations using CUBE, focusing on the Palm Jumeirah area and Dubai Business Bay, respectively.

Retrofitting is an approach in urban planning that takes as its basis the current condition of a city or area offering strategic as opposed to wholesale interventions in order to provide quick, costless (or cost-effective) and effective solutions to persistent or emerging needs. These interventions may be permanent or subject to change depending on the resources used to achieve them. Yet, retrofitting is fundamentally conceived as a constitutive effort integrated in a wider strategy for urban development (Hodson and Marvin 2016). This paper explores potential pathways for retrofitting via three mutually reinforcing retrofitting strategies to upgrade the walkability experience of Dubai's street infrastructure with particular attention to the impeding conditions of the current COVID-I 9 pandemic situation.

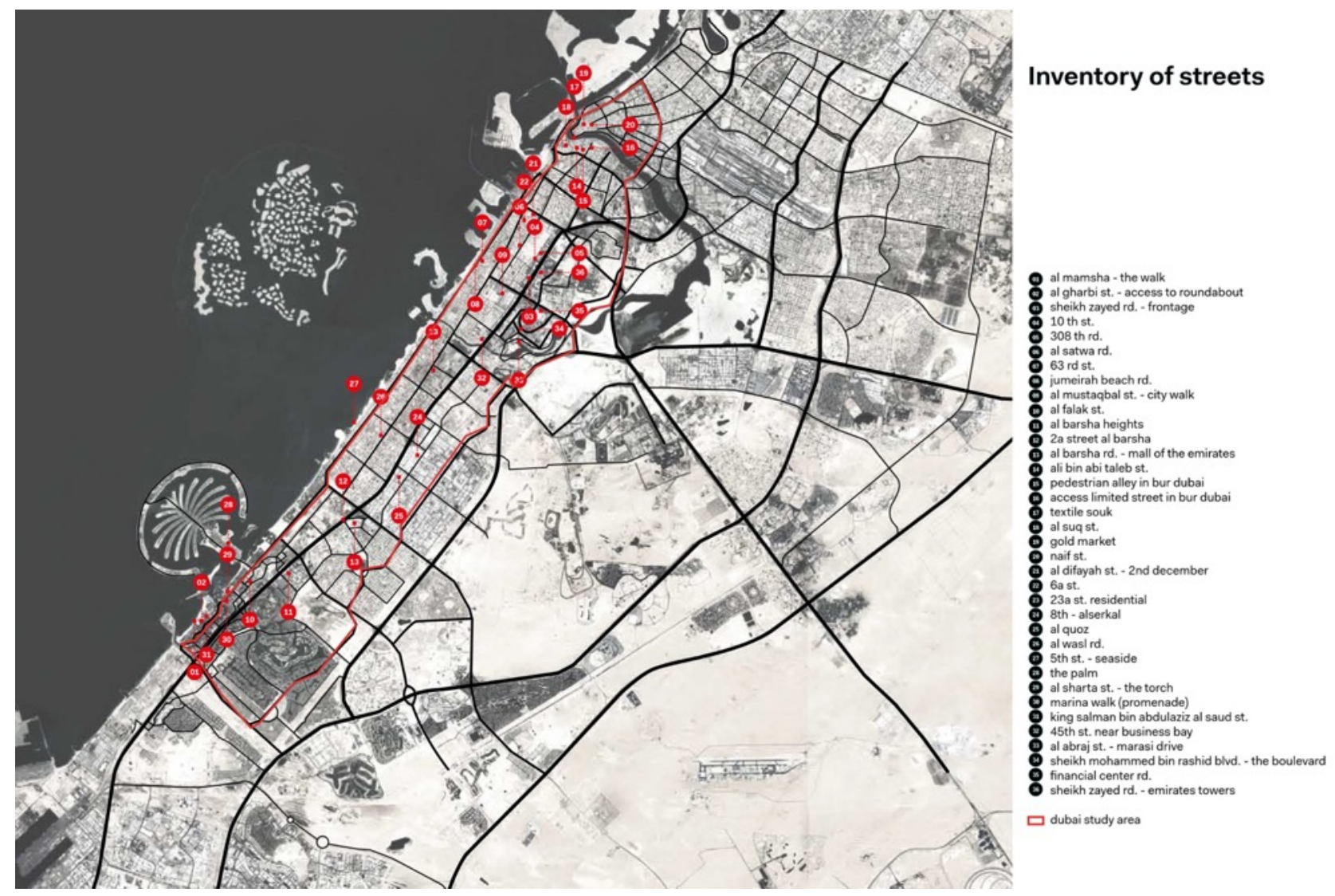

Figure 2. Inventory of streets and main area under study - property of Systematica srl

In essence, the research aims to highlight the redemptive potential of the street as a means to enhance Dubai's public space offering and walkability prospects. No clearer is this redemptive potential than in our current global moment, whereby new emerging 
health regulations necessitate that we reorganize our streets to enable safe and efficient mobility with the least negative impact on the environment. This is particularly evident in the growing global plea to liberate more street space for pedestrians and cyclists in order to allow for sufficient social distancing while ensuring the minimum required space occupied per capita (Comune di Milano \& AMAT 2020; NYC Department of Transportation 2020; Koronavirus Budapest 2020; World Health Organization 2020; Honey-Rosés et al. 2020). It is for this reason that we focus explicitly on these principles as avenues for reshaping Dubai's infrastructure to (a) restore city life in the near future without compromising public health conditions, and (b) redirect the tracks of the city's mobility trends towards a more resilient structure on the long run.

\section{'Reading' the city}

Contemporary digital mapping tools have come to the aid of urban researchers and planners in the time of COVID- 19 by allowing them to quantify and visualize the implications of the urban structure on the pandemic and vice versa. During a time when movement and public mixing have quickly become antidotes to public health, and mobility structures have been overturned by unprecedented stipulations, the need for integrated and coordinated efforts to quickly reorganize the way people move in the city has been amplified. In the first order, mapping tools are effective instruments for defining the magnitude of a given problem. In Milan for example, a Systematica-launched effort to map the entire city's pedestrian infrastructure -taking sidewalk width as the variable factor-provided a basic overview of where it was possible to support social distancing practices across the city (see Milan Sidewalks Map). Assumptions based on local regulations for safe interpersonal distance provided the basis for measurement. By categorizing the city's sidewalks on a progressive scale from 'extremely unsafe' to 'ideal', the study revealed that about $45 \%$ of the city's pedestrian infrastructure was unfit for adequate social distancing (Systematica 2020). In the following section, we turn our attention to several walkability indices that are useful in reading the city and streets of Dubai.

A prominent method of assessing street safety and comfort to pedestrians is the Pedestrian Level of Service (PLOS) metric. Starting from a detailed GIS model, the PLOS method is a useful way to detect pedestrian-friendly street segments at city scale. The result of this application is a color-coded map of the city's streets ranked from PLOS A (most pedestrian-oriented segments) to PLOS F (the most car-oriented), as seen in the mapping of Dubai's Palm Jumeirah area (figure 3 ).

While the PLOS metric can tell us a lot about the level of comfort of available pedestrian space, other measures are used to calculate how much of an area's services can actually be accessed on foot by its own residents. This concept has been strongly iterated in recent international city plans and proposals under the now-famous slogan of the 'I5-minute city' (Paris En Commun 2020; Comune di Milano 2020; City of Portland et al. 2012; Victoria State Government 2020). The I5-minute city or 'complete neighbourhoods' concept stems from chrono-centric views of the city that promote an urban lifestyle change by reintroducing the choice of proximity (Moreno 2020). This concept has become particularly popularized in the wake of the ongoing pandemic as a successful model for cities to follow if they hope to alleviate car dependency and compensate limited public transport occupancy rates under social distancing norms. 
The Redemptive Potential of the Street.

A|PLOS values across study area

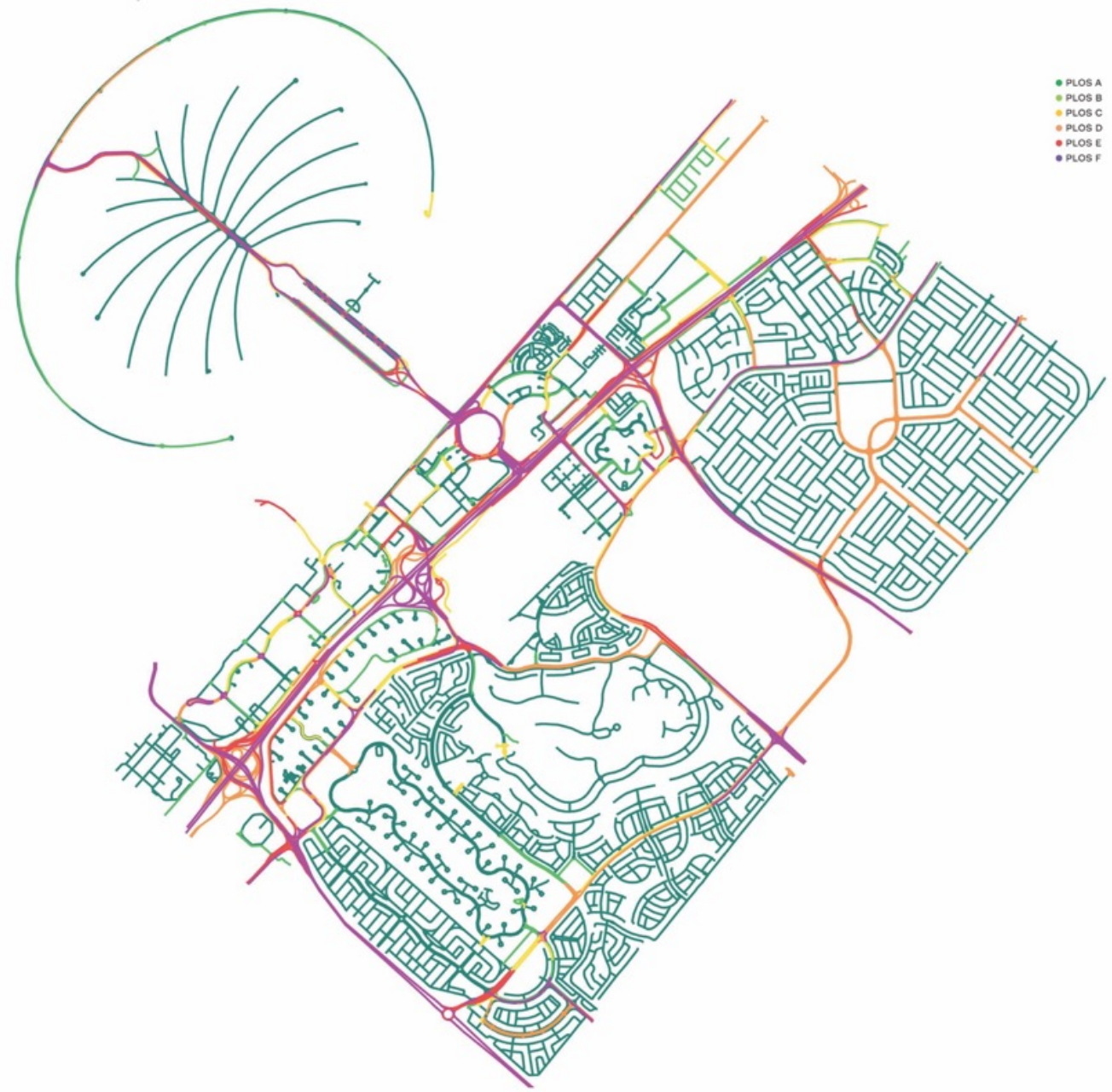

B | Factors affecting PLOS values (+ve/-ve)

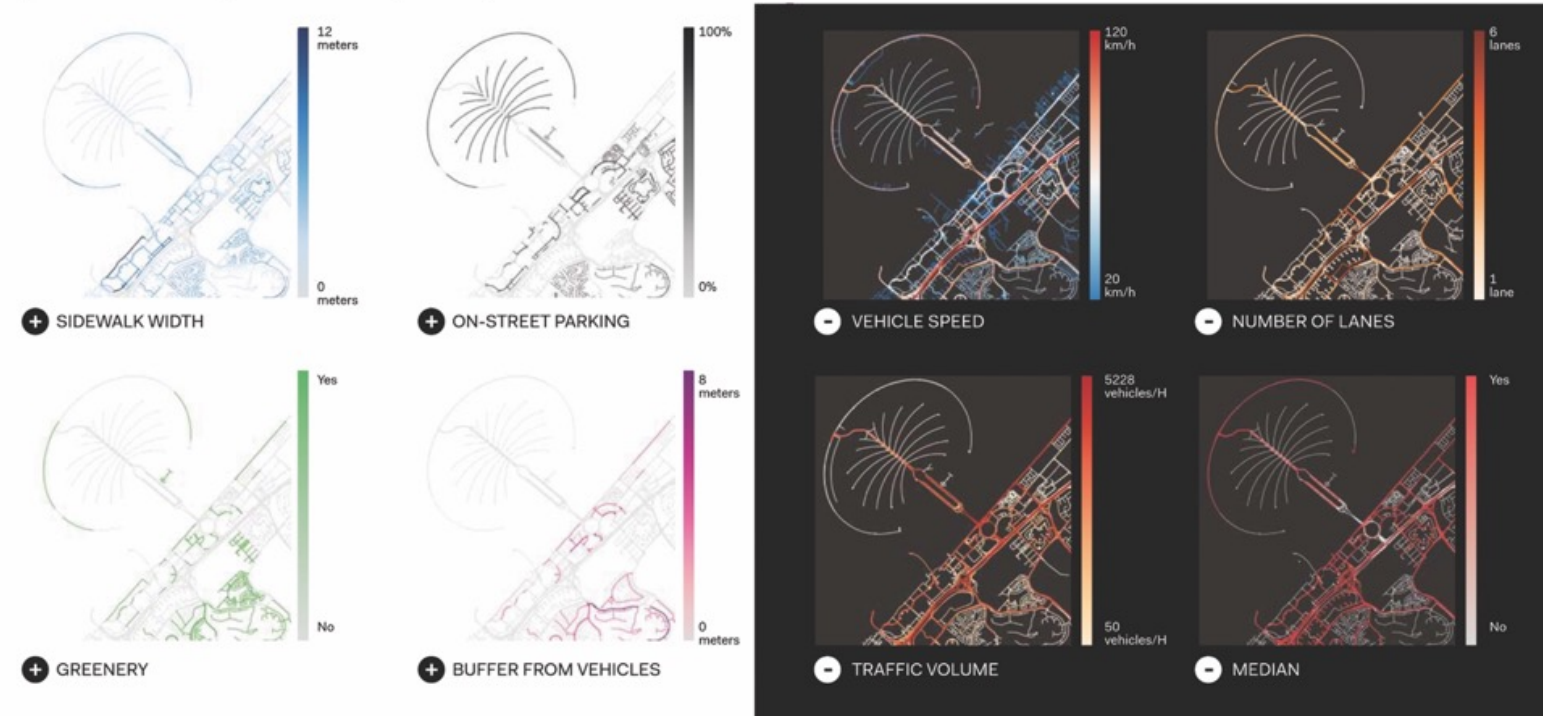

Figure 3. PLOS mapping and component analysis of the Palm Jumeirah area - property of Systematica srl

72 | The Journal of Public Space, 6(I), 202I | ISSN 2206-9658

City Space Architecture / UN-Habitat 


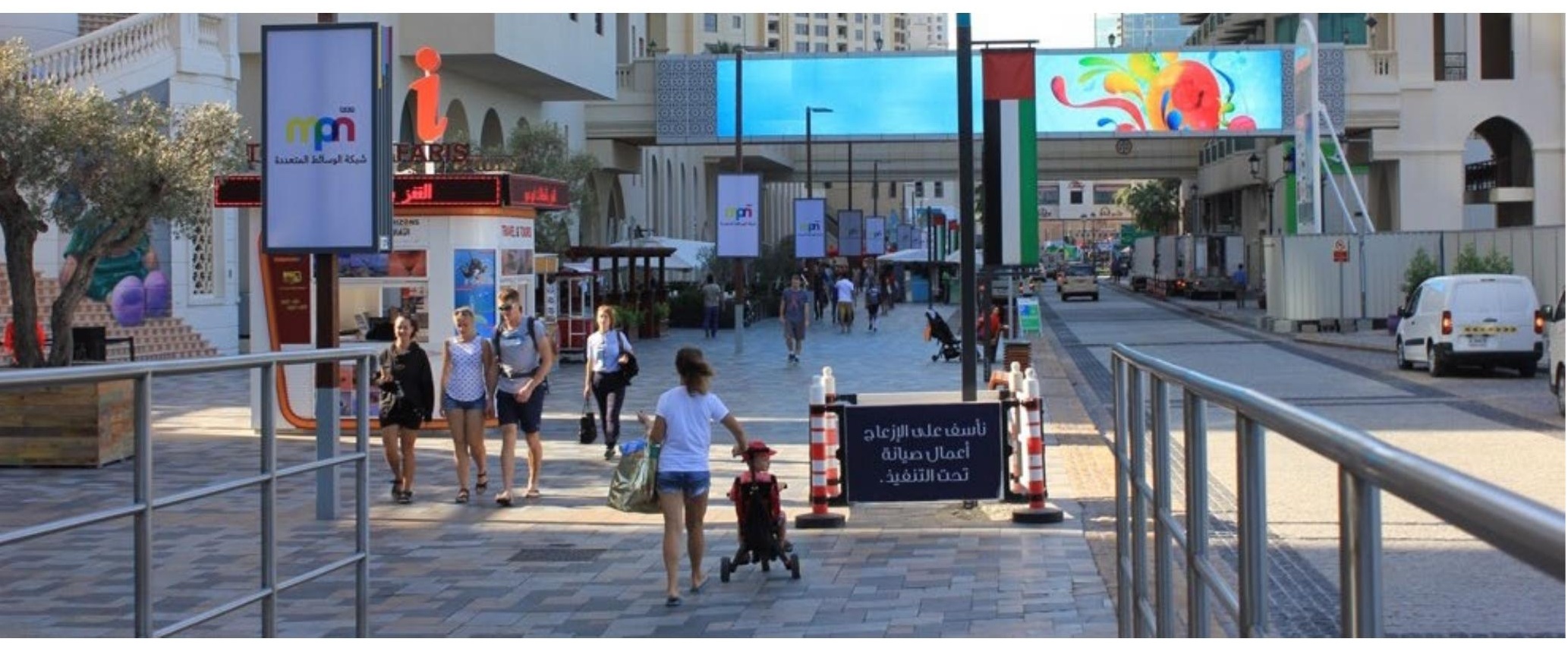

Figure 4. The Walk or Al Mamsha Street in Dubai - retrieved from www.liberallandscape.org

One of the many metrics developed to measure neighbourhood access to services on foot is Walk Score®. Based on pedestrian catchment areas and sophisticated linear distance models, Walk Score conceptualizes the idea that distance from amenities strongly influences travel modal choice. Scored on a scale of $\mathrm{I}-\mathrm{I} 00$, the metric ranks areas on the basis of their capacity to host services reached on foot: 0-20 is a low score that indicates areas where most trips require a car, whereas 'Walker's Paradise' is the term given to the highest scores between 80-100 where residents of an area can expect to make most of their essential trips on foot. In Dubai, an example of Walker's Paradise is The Walk, or Al Mamsha Street. The famous pedestrian street seamlessly connects a large number of retail and hospitality venues while providing ample, thoughtfully considered space for pedestrians to roam (figure 4). Not far from there, King Salman Bin Abdelaziz Street represents a 'Somewhat Walkable' Street (score range of 50-69). In spite of its strong connection to services and facilities, the tram line bisecting the road creates a physical barrier for pedestrians with limited crossing points, which significantly increases travel time and hinders walkability. The Financial Center Road, on the other end, is a clear example of a Car-dependent street (0-20). With its high congestion levels and a complete lack of an active frontage to attract pedestrians, the street is hardly ever used for walking or recreational use. Apart from workers resting in the shade of the large elevated road structure across from The Dubai Mall, pedestrian activity is rare. These examples elucidate the idea that the physical environment of a street is not enough to render it walkable; land use structure and high connectivity levels are equally important factors.

Network theories are another branch of metrics, developed to understand how locations of services can be optimized for pedestrian accessibility. Space Syntax, a tool developed in the 1970's by Bill Hillier and other researchers at UCL, which has since been optimized by various generations of researchers, is one such renowned model. Space Syntax essentially visualizes the city as a legible system of nodes and relations. Its innovation 
particularly stems from its elaborate and sophisticated approach to conceiving route choice decisions by pedestrians. It goes beyond traditional, rational assumptions of travel choice as a mere equation of time and distance and considers the cost of perceptive qualities such as 'angular deviation', whereby the relative cost of turning is taken into the equation as well. By determining the most convenient paths for pedestrian movement, the model can be calibrated to detect the most suitable locations for different services using 'angular choice'; a method that highlights street segments that are inherently important parts of different types of journeys within a specified area (figure 5). A choice map set at $250 \mathrm{~m}$ highlights ideal street segments for neighbourhood-scale services, accessible on foot within a short walk from home. Small local businesses requiring high pedestrian footfall could benefit greatly from locating along these paths. The choice map of $750 \mathrm{~m}$-the distance roughly corresponding to the 20 -minute time limit most people are willing to walk to meet daily needs- shows the most convenient routes for longer walking trips (Gunn et al. 2017). At $2500 \mathrm{~m}$, we see the routes most suitable for cycling trips, while at ' $n$ ' meters (produced by setting the limit of angular choice to the maximum), we can distinguish the path segments that are most convenient for long-distance car-based trips. Pedestrian simulations have widely been restricted to emergency situation modelling. They are used to imagine evacuation scenarios of public transit stations, stadiums or packed entertainment venues, but can also be extended to determine safe walking routes in public space - particularly in light of the current pandemic situation. Pedestrian modelling is therefore a valuable tool to understand how people move, locate potential choke points and plan for them accordingly. In an exercise using CUBE, a software developed by Citilabs, it was possible to model pedestrian flows at Business Bay in Dubai using the same tool that was once used to predict the movement of cars and public transport, reprogrammed to predict pedestrian flows (figure 6). The system overlays a zoning model with pedestrian desire lines to predict primary axes of movement. If programmed to accommodate social distancing requirements, this tool can prove highly useful in organizing public space navigation during the pandemic crisis such as to allow for safe and efficient pedestrian flow within public space and at key access points.

\section{'Understanding' the city}

In this section, we turn to some insights from direct observation and site survey that resonate with the aims of this research. As previously noted, the implication of how much sidewalk space is available for users is essential to understand whether pedestrian movement could inflict harm on pedestrians in the form of contagion risk to airborne diseases such as COVID-19. Though not a full-fledged street-by-street survey, the limited 36-street study scans a variety of street typologies across Dubai: from local access roads to several-lane collector roads, and from highly pedestrianized to highly car-oriented streets. The selection of the surveyed streets was specifically designed to reflect the diversity of Dubai's urban core between old and new, active and inactive. In the following section, we look particularly at how allocation of street space to different functions (and particularly to pedestrian movement) can impact usability and walkability of that street. Next, we investigate the role of junction spacing and pedestrian crossings in facilitating walking and reducing walking time/distance. Both elements have great implications on the city's potential to provide a more pedestrian-fitting landscape during the pandemic and beyond. 


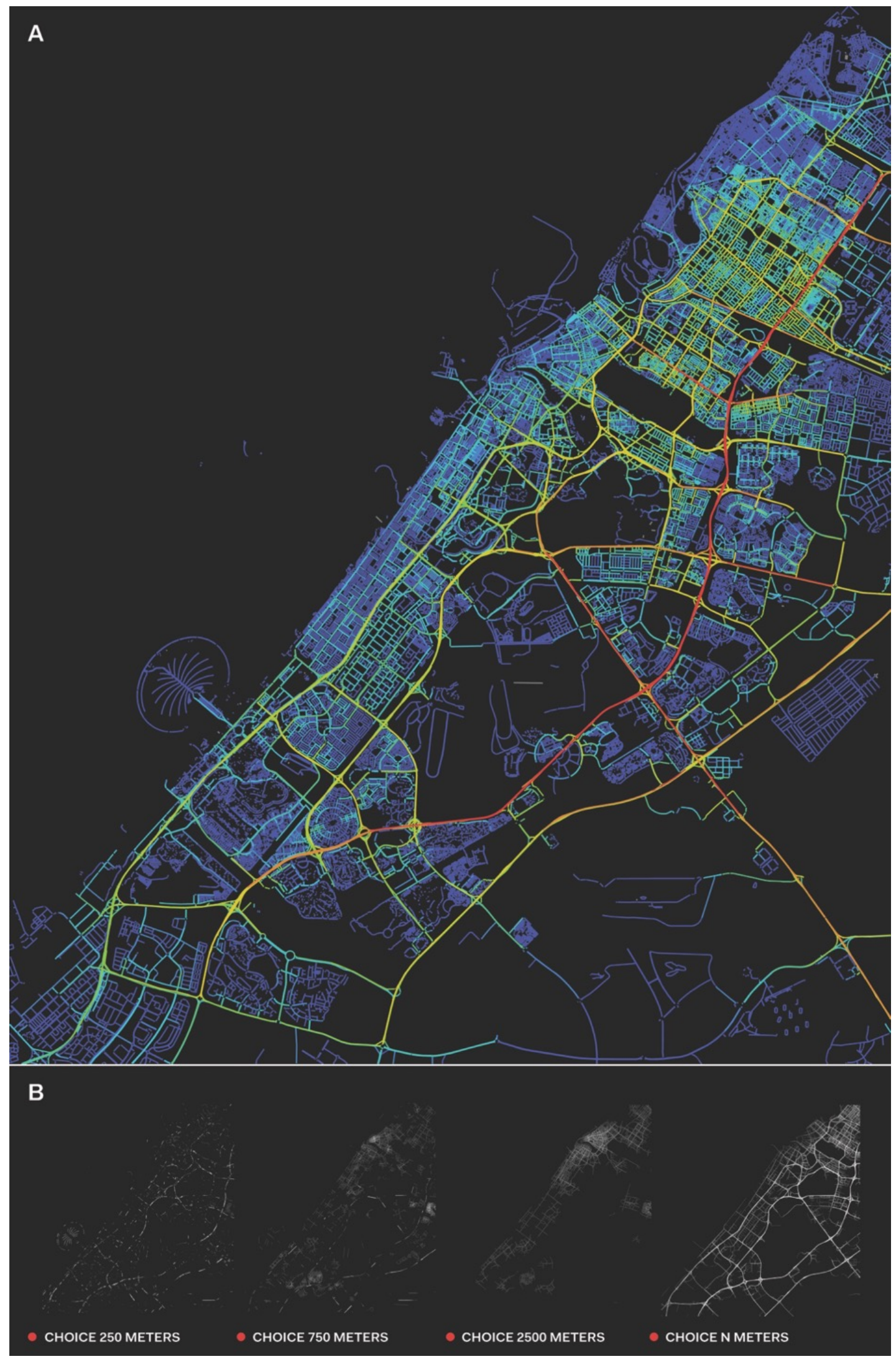

Figure 5. Space Syntax integration and angular choice models - property of Systematica srl 


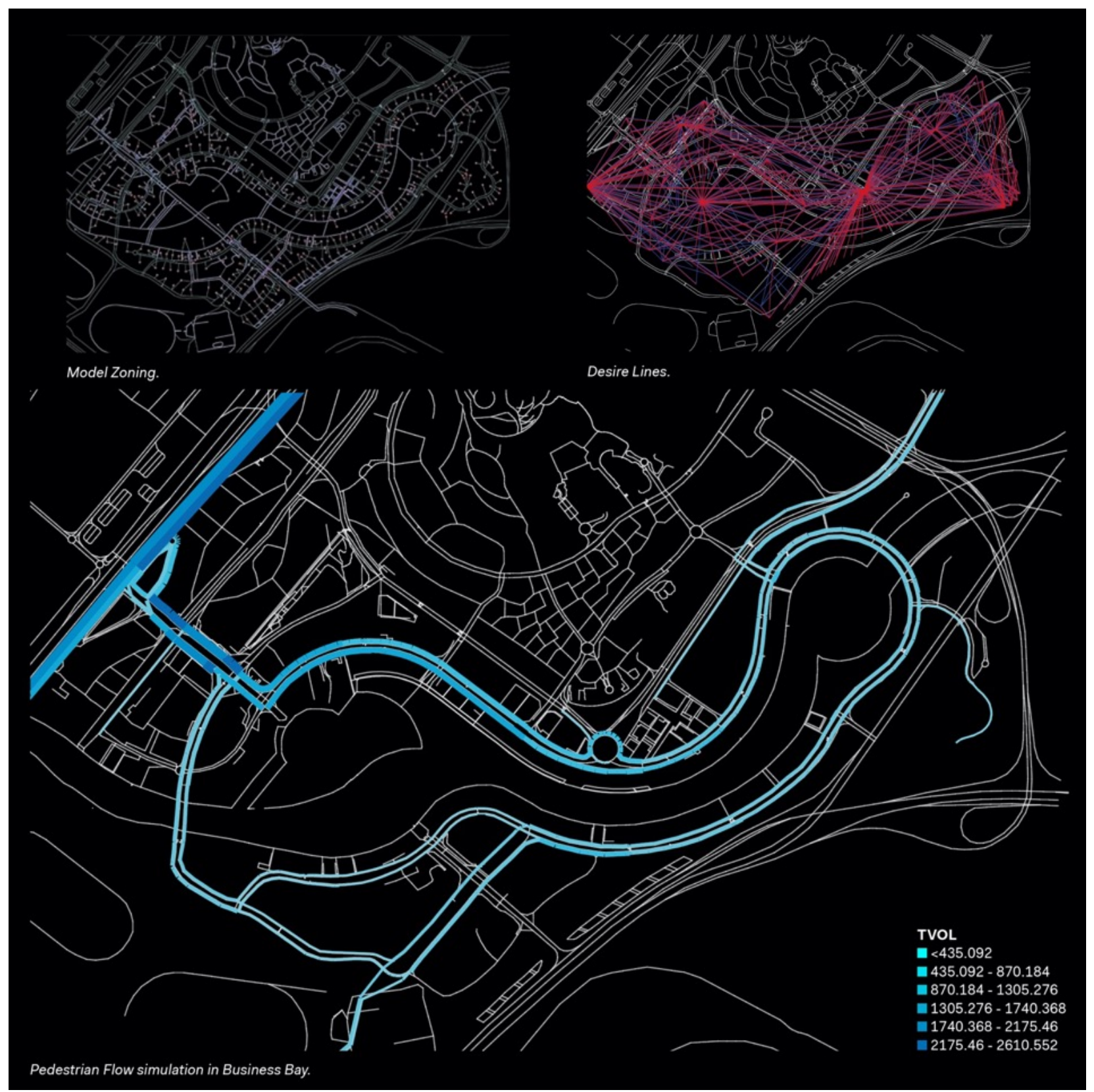

Figure 6. Pedestrian flow simulation for Business Bay in Dubai - property of Systematica srl

Across Dubai, numerous streets are handed over to vehicles with only the minimum space allotted for other ongoing street activities. When it comes to large boulevards or several-lane highways, this discrepancy is emphasized, making whatever leftover pedestrian space seem contracted in comparison. After surveying 36 streets across Dubai with contrasting profiles (figure 7), the effects of the distribution of street space became clear: the analysis revealed that the way a street is used is strongly related to how street space is distributed among its different users. 


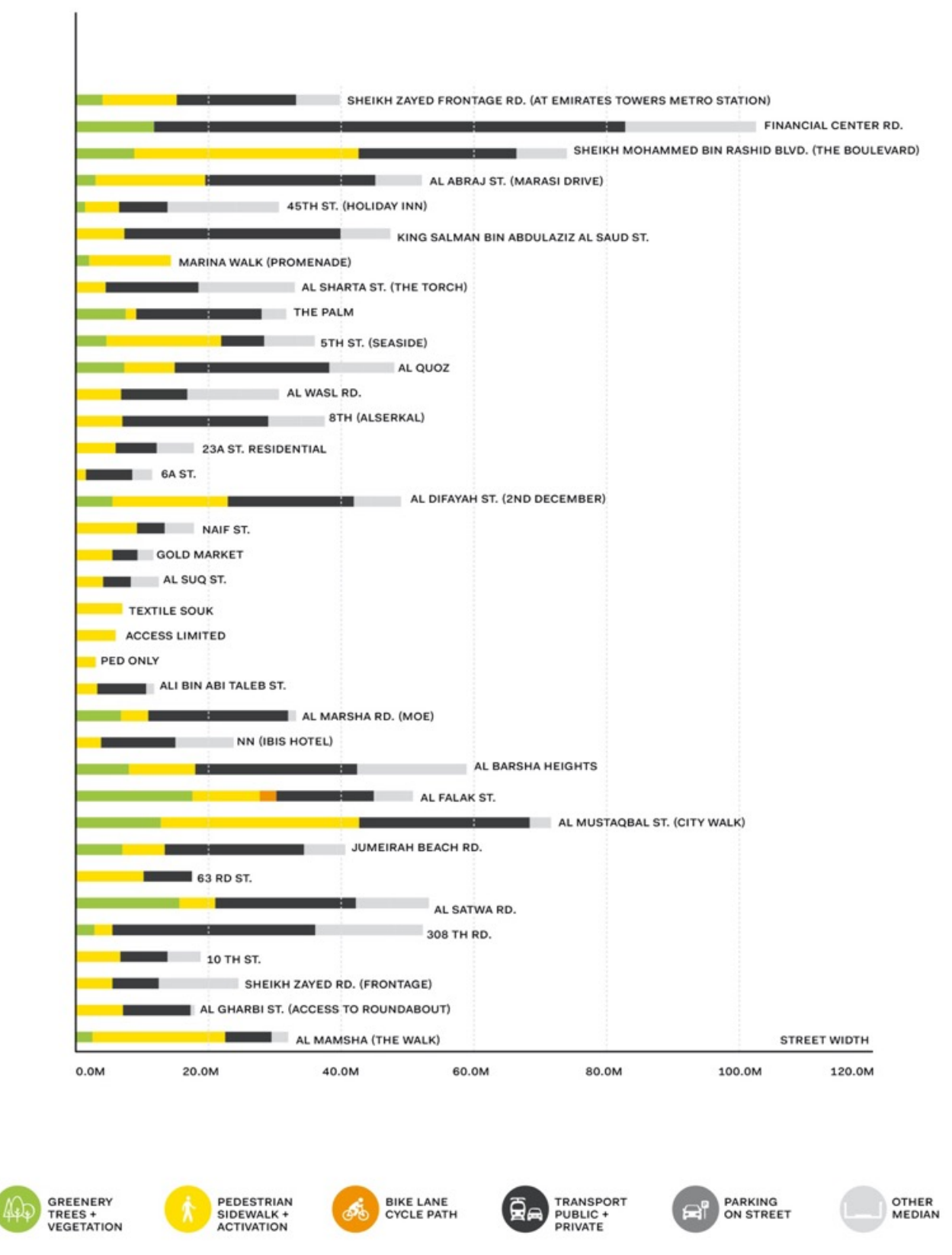

Figure 7. Allocation of Space on Dubai streets by absolute distances - property of Systematica srl

Upon deeper speculation, it also became clear that the amount of space allotted to vehicles (or the ratio between vehicular and pedestrian space) is just as important. Regardless of the actual width of sidewalks, wide vehicular corridors are direct contributors to noise and air pollution, which work to diminish the attractiveness of walking and consequently footfall for at-grade commercial spaces. To take an example, while more than 30 meters are dedicated to pedestrians on famous pedestrianized streets such as the Boulevard and City Walk, large streets such as Al Wasl Road, Al 
Barsha Heights and $308^{\text {th }}$ Road - all major arteries of over 40 meters of width - have very small shares of sidewalk space with respect to road space, and thus very low pedestrian activity. In other examples such as Al Satwa Road, pedestrian activity prevails despite limited infrastructure due to several factors, amongst which are the high density and a higher availability of public transport services than most areas. A reading of the streets that considers the relative proportion between pedestrian and vehicular space highlights the importance of allotted street shares over actual sectional widths. Following this classification (figure 8), it becomes easy to identify the general orientation of streets with respect to walkability by categorically assimilating them based on their interdependent space provisions.

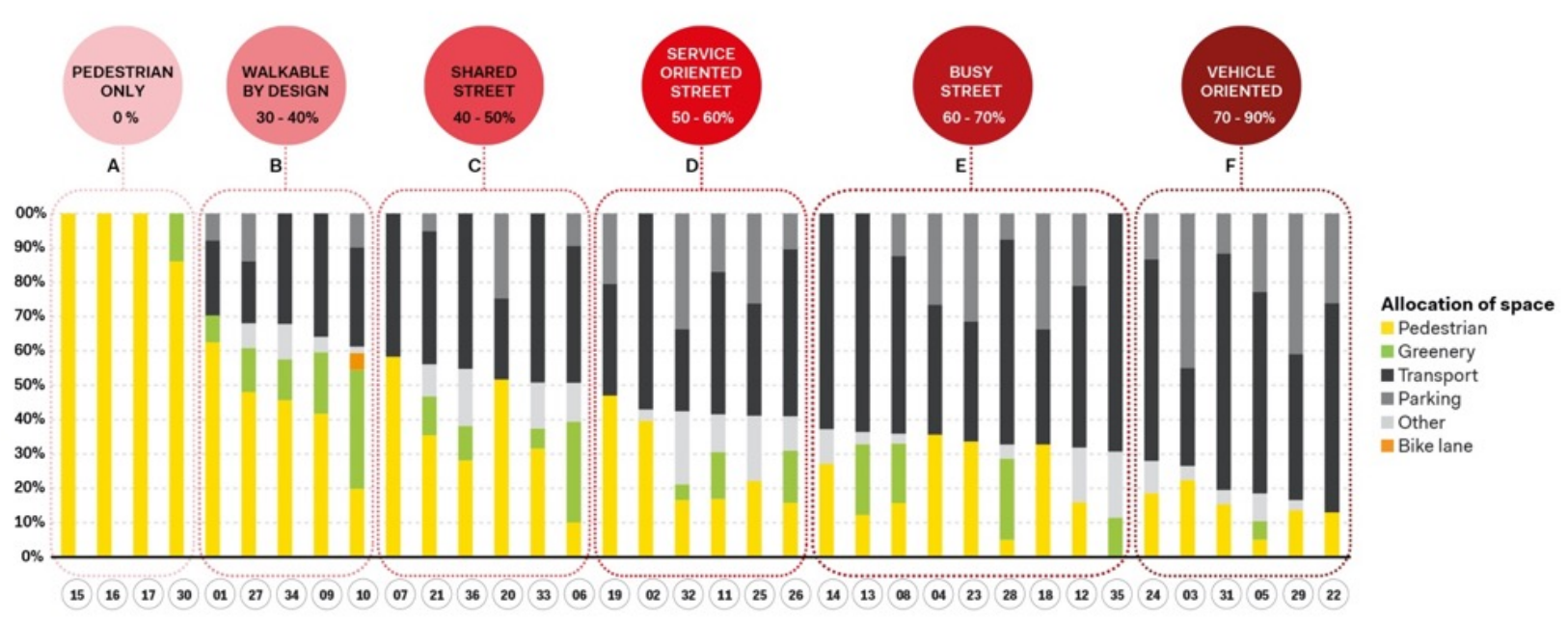

Figure 8. Allocation of Space of Dubai streets by relative proportion (percentage) - property of Systematica srl

The rankings run from A: the most pedestrianized streets; to $\mathrm{F}$ : the most car-oriented. Streets falling into the highest Category, A of totally pedestrianized spaces include the Textile Souq and the Waterfront Promenade in Marina. These streets present pedestrians with an opportunity to roam freely without concern over contact with vehicles. The area of Bur Dubai where vehicular access is limited to delivery drop offs is another such case. With up to $60-70 \%$ of space dedicated to pedestrians, as well as designated supporting features reflected in choice of material and a step-free environment, Category B streets are also designed with walkers in mind. Examples include The Walk, The Boulevard or the main street cutting through Citywalk. The third category, $\mathrm{C}$, is where we find a balance between pedestrian and vehicular space (about 50-50). Service-oriented streets (D) are where more than $50 \%$ of space is dedicated to vehicles and which do not effectively encourage pedestrian movement (examples are Al Barsha and Al Wasl Road). Busy Streets (E) are where traffic flows are generally high with vehicles occupying up to $70 \%$ of space. These roads are not particularly inviting to pedestrians and tend to lack ground floor land use, such as in the case of the Jumeirah Beach Road.

Not all street groups should aim for higher pedestrianization. Some of the roads in Group F (vehicle-oriented streets) -with more than $70 \%$ of space dedicated to vehicles- 
are specifically designed to facilitate fast and efficient vehicle flows and would thus be compromised should their vehicular lanes be restricted or given over to pedestrians. A scattered plot diagram (figure 9) comparing pedestrian space to the full street section identifies cases based on their perceived need for intervention, as shown in the legend.

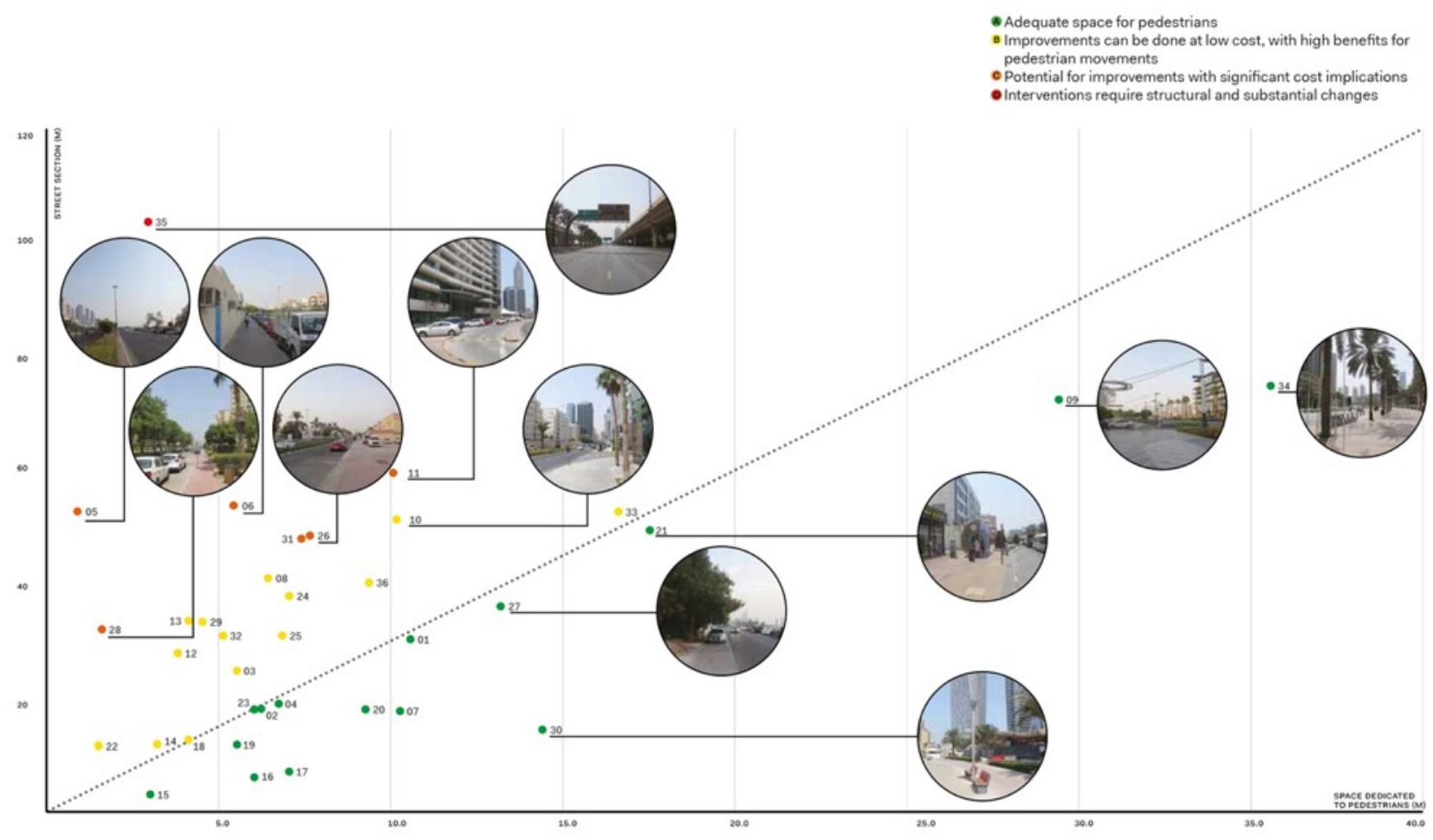

Figure 9. Ratio between space dedicated to pedestrians and full street section as basis for intervention property of Systematica srl

The UAE is one of the most stringent countries worldwide when it comes to social distancing standards. At two meters of required interpersonal distance in outdoor spaces, the value is double the recommendation of the World Health Organization and other global cities (UAE Government 2020; Matthews 2020). With that mind, and based on the model conceived for the Milan case study, we could infer that at least 3.4 meters of sidewalk width are required for acceptable pedestrian movement on Dubai's streets. Some main corridors whose sidewalks do not adhere to this minimum width are the Financial Centre Road, Sheikh Zayed Road, The Palm and $308^{\text {th }}$ Road.

While sidewalk space analysis is useful in determining how safely pedestrians can travel with adequate spacing and how conducive the environment is to walker's comfort, junction spacing and pedestrian crossing analyses can indicate how efficiently they can travel. Low junction spacing and a high frequency of pedestrian crossings work to permeate the urban grid, encourage through movement on roads that are not otherwise designed for comfortable walking and provide more alternative routes for walkers (thereby reducing overall contact and enhancing route efficiency). Following, we examine two street examples to showcase the importance of proper and adequate planning for pedestrian crossings. 
The Redemptive Potential of the Street.

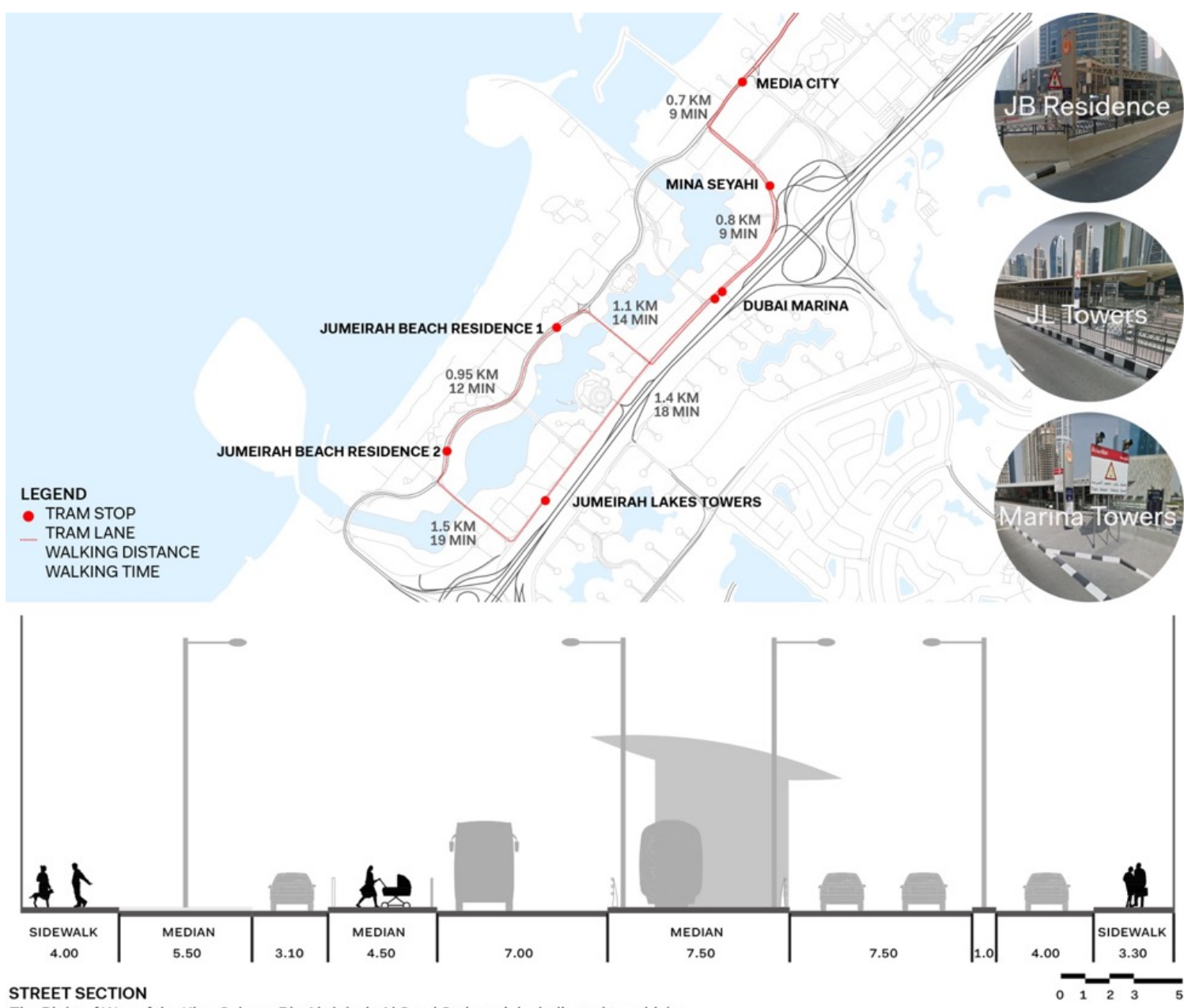

STREET SECTION

The Right of Way of the King Salman Bin Abdulaziz Al Saud St. is mainly dedicated to vehicles.

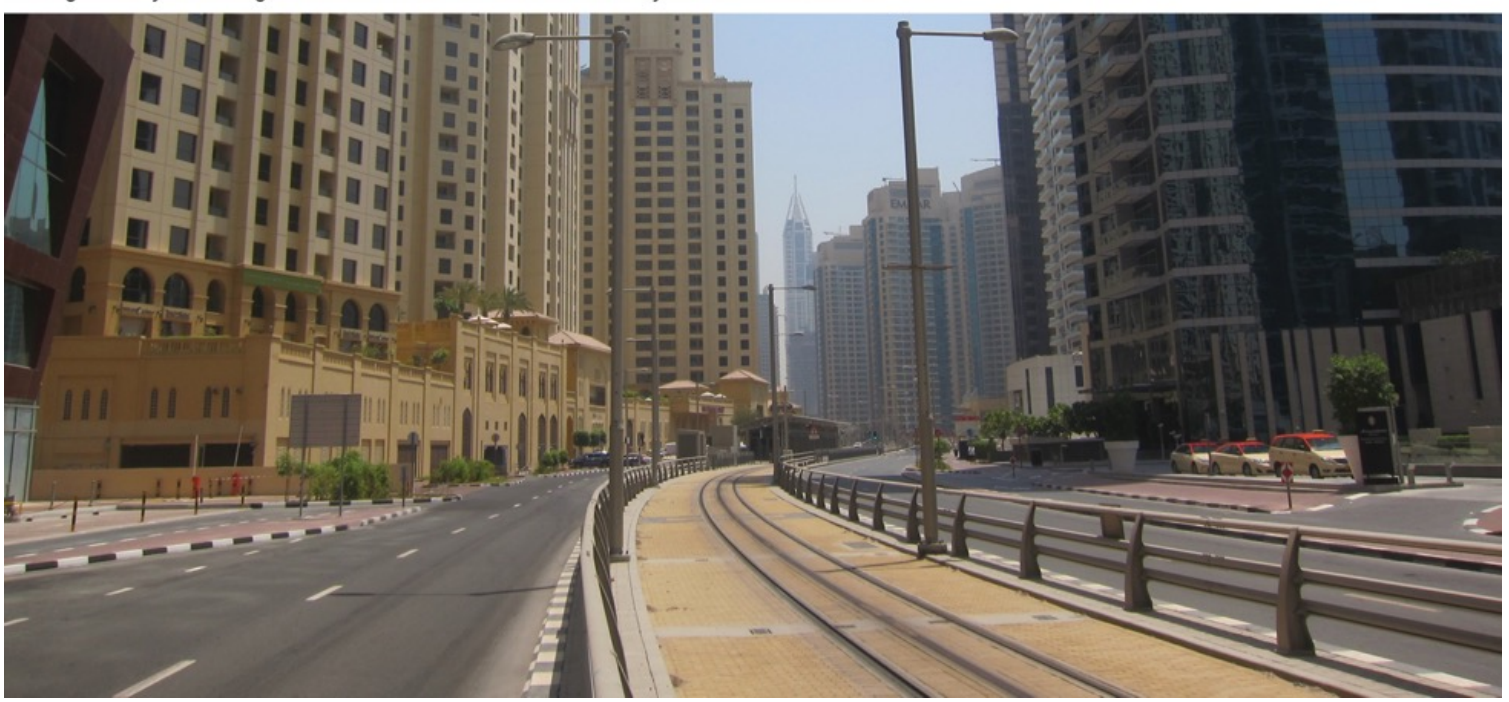

Figure 10. King Salman Bin Abdulaziz Al Saud Street tram line disconnection - property of Systematica srl

The first case is the King Salman Bin Abdulaziz Al Saud Street. As mentioned in the previous section, this street is ranked as 'somewhat walkable' due to the physical barriers limiting crossing on both sides of the tram line. Introduced in 20I4, the Dubai 
Tram's 10-kilometer network of eleven stations is a positive addition to Dubai's transport infrastructure. It is also commended for its progressive approach to power supply via ground connection. The third rail technical solution, which is only applied in a few tram line systems around the world, drastically improves urban quality by eliminating overhead cables. However, despite technical progress, the design falls short in delivering a seamless terrain for foot traffic. With both sides of the line fenced off, crossing is restricted to junctions and station points, which are often 500-600 meters apart (figure 10). The result of these barriers is excessively channelled pedestrian movements, which both decreases permeability and route efficiency and increases contact between people at each intersection. A more permeable and seamless connection between infrastructure for the tram and other modes of traffic that relies on advanced safety measures would eliminate this hazard.

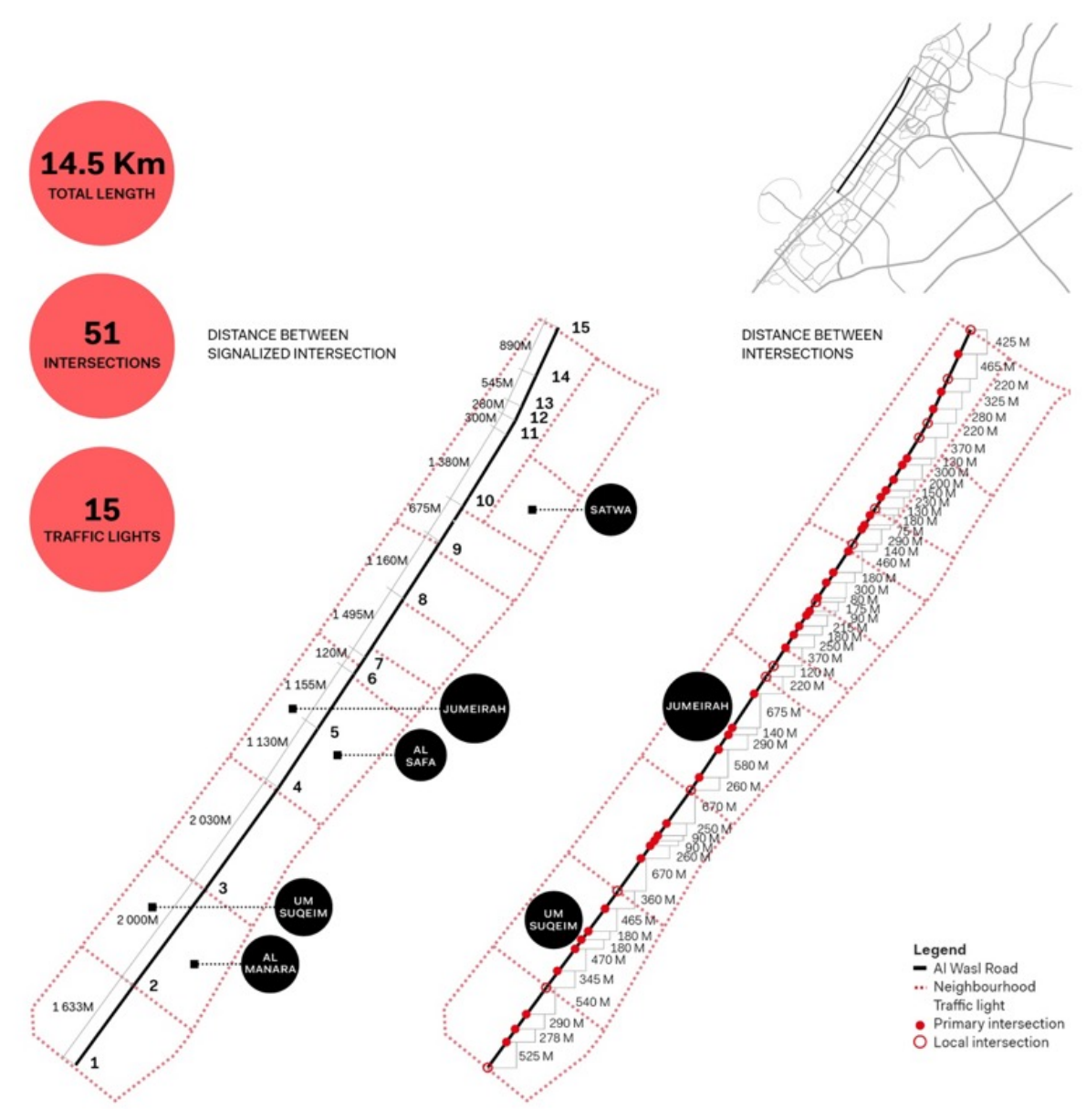

Figure I I. Al Wasl Road Junction Spacing diagram for the Al-Satwa side - property of Systematica srl

Al Wasl Road is a great case study for the role of junction spacing and its relationship with land use structure. It is a vast 50-meter-wide artery running across the city from North to South and with several changing profiles and characters. Here we focus on two opposing sides: the Al-Satwa side and the Um Suqeim side. Driving down from the $2^{\text {nd }}$ December Road to Um Suqeim Street in the Al-Satwa area, one encounters a 
The Redemptive Potential of the Street.

vibrant and bustling mixed-use neighbourhood supported by active ground floor use. The street supports both commercial and public functions such as the Satwa Grand Mosque and the Satwa bus terminal along this northern $15 \mathrm{~km}$ stretch. However, past Um Suqeim Street and extending into the Um Suqeim area, this scene gives way to a low-density residential environment with little to no pedestrian activity. This discrepancy is echoed in the frequency of junctions and signalized intersections on each side, as discussed in results (figure $\mathrm{I} I$ ).

A third category of observations with a critical (if not fatal) relationship with walkability, and which is a focal point particularly for the fact of Dubai's hot desert climate, is shading. The harsh climate conditions make walking in the city difficult at least for a third of the year - from June to September. Thermal comfort levels on streets depend on a variety of factors relating not just to climate, but to physical urban structure as well as factors of psychological adaptation (Nikolopoulou and Steemers 2003). Asphalt, for example, is known to contribute to adverse microclimatic conditions. For that reason and for the advantage of extended shading by adjacent buildings, narrower streets make for better walking conditions, as does the reduction of parked cars on the street, which also contribute to a heat island effect. In Dubai as in elsewhere, pedestrians naturally divert their routes to areas of higher thermal comfort such as the shaded side of the street or areas close to at-grade retail where air-conditioning can be felt through entrances. Other tactics observed on Dubai's streets include using a sunshade or umbrella to minimize direct sun exposure in areas where no other shading features are available (figure 12).

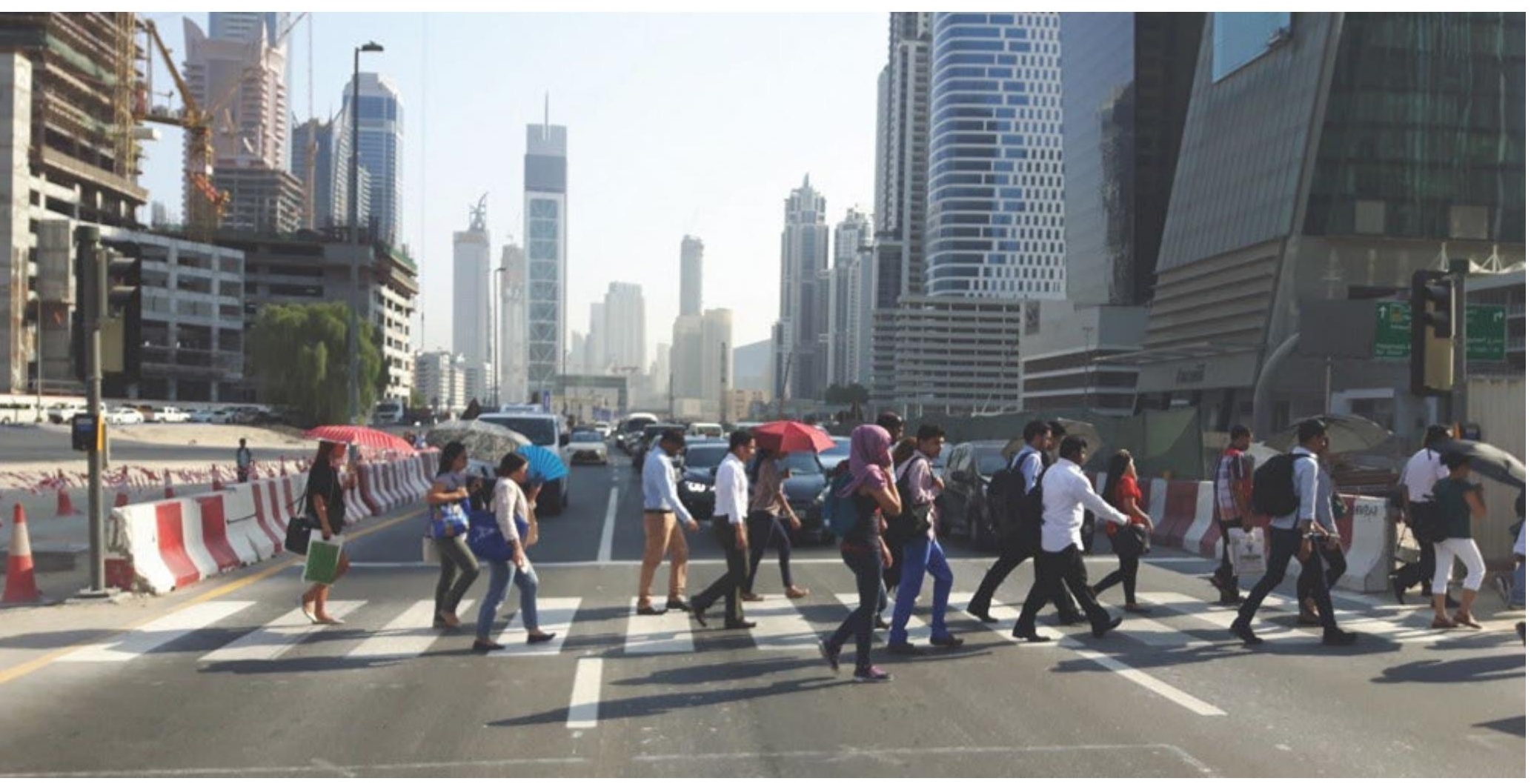

Figure 12. Pedestrian crossing in Dubai; pedestrians using umbrellas to limit heat exposure - property of Systematica srl

82 | The Journal of Public Space, 6(I), 202I | ISSN 2206-9658 City Space Architecture / UN-Habitat 
Psychological adaptation research suggests that the amount of time spent walking in harsh climatic conditions influences perceptions of thermal comfort. Repetitive or frequent relief points (such as shaded or cooled areas) along a walking route were found to significantly improve users' thermal comfort levels and contribute to extended walking times (AI Sabbagh 2019; AI Sabbagh, Yannas and Cadima, 2016). Greenery and vegetation also provide excellent relief from the harsh heat. However, it must be noted that landscape planning is a critical task that has direct implications on the Right of Way. For example, tall trees require large footprints which cannot run under carriageways. Trees planted on medians therefore effectively enlarge the crossing area between sidewalks rather than keeping it compact. Coordination between these competing design elements is thus essential for proper shading utility. Perceived control is another known psychological adaptation feature that has direct effects on how long people spend outdoors or in a given open space. In cases where there is a variety of options for shading and seating, where people could choose their positions with respect to shade, people have been found to spend more time outdoors than in cases where options were limited, or there were no options at all (Nikolopoulou and Steemers 2003). In one such experiment, Nikolopoulou and Steemers (2003) found that people spent more than three times as long in a space where there were several shading/seating options as those in areas where no options were present, under the same climatic conditions. One of the ways by which the city of Dubai provides shelter from the harsh summer heat is via air-conditioned bus stops. These climate-controlled spaces were introduced in the city in $\mathbf{2 0 0 7}$ as a way to mitigate the risks of standing in the heat and thereby encourage public transport ridership. Each structure is an enclosed glass-fronted space holding 8-10 seats and cooled via an air handling unit. In busier stops, two of these standard enclosures could be found side by side to increase occupancy (figure 13).

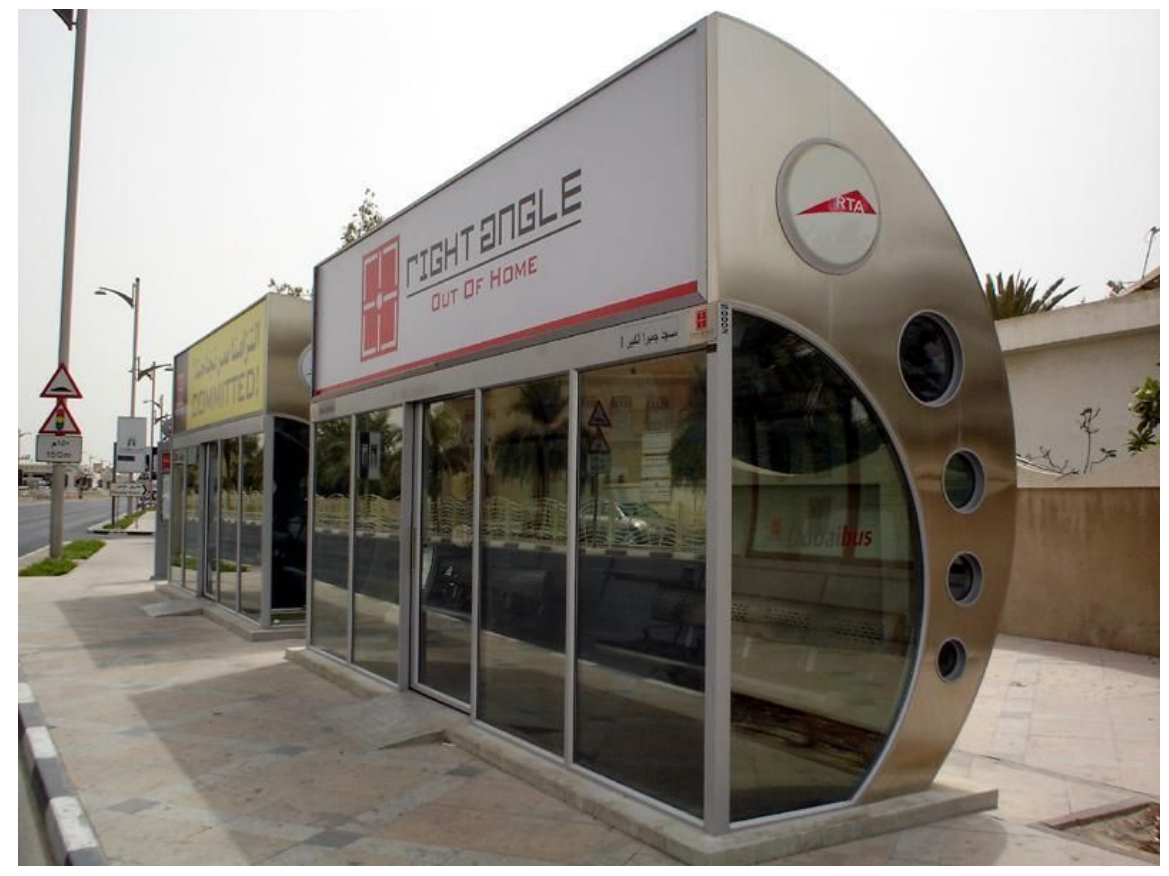

Figure 13. Air-conditioned bus shelters in Dubai - retrieved from www.arabianbusiness.com 
This paper presents the view that these confined climate-controlled spaces have limited viability in the long run and could present more harm than good in the current pandemic crisis. In retrospect, the configuration of this type of waiting space goes against the grain of recent health recommendations by global health authorities. It confines a group of people in a small enclosed space for a significant amount of time where the primary source of ventilation is air-conditioning. Recent studies have suggested that air-conditioning, which essentially redistributes air within a closed area, could prompt the circulation of the COVID-19 virus (and other air-borne pathogens) within the space (Lu et al. 2020; Heil 2020; Bata et al. 2020). Moreover, thermal adaptation studies suggest that the excessive reliance on climate-controlled indoor environments lowers subjects' ability to overcome outdoor conditions due to high temperature differences (Al Sabbagh et al. 2016). This is particularly relevant in the Dubai case were temperature differences during the summer months reach magnitudes of $20 \mathrm{k}$ - well above the advised $4 \mathrm{k}$ threshold (Al Sabbagh 20l6). Given this information and the shelters' limited capacity to accommodate higher demands in the future, a design review of these shelters is recommended.

Another critical design aspect of Dubai's bus stop is its lay-by, or bus pull-out, typology. The lay-by typology is generally considered a suburban typology; it is used in situations where public transport is deprioritized in comparison to private vehicles. In dense urban centres, the pull-out bay area is generally avoided to eliminate unnecessary operational time delays of pulling in and out. Aside from operational concerns, the pull out design has some negative unintended consequences on walkability as well: by essentially cutting away space from the sidewalk, it creates a bottleneck in pedestrian flow in the space behind it, as seen in this case on $2^{\text {nd }}$ December Street (figure 14). A revision of bus stop typology and shelter design could therefore significantly improve waiting time and contagion risk for Dubai's public transport users.

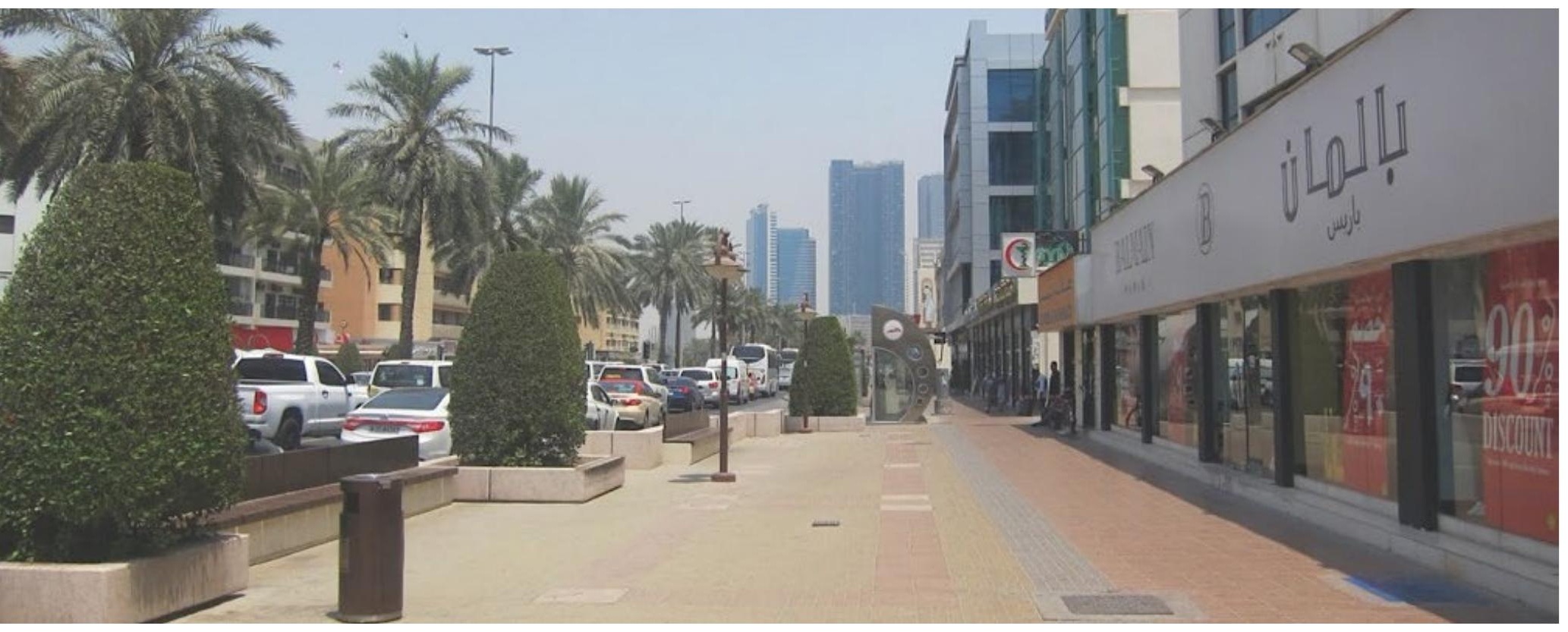

Figure 14. Lay-by bus stop typology on 2nd December Street - property of Systematica 


\section{Main results}

The Pedestrian Level of Service analysis of the Palm Jumeirah area showed varied results across the development, from PLOS A to F. The majority of the streets by area (about $60 \%$ ) lie in the highest pedestrian categories $A$ and $B$; while about $15 \%$ are streets of lowest pedestrian service: PLOS E and F. Smaller and more localized street segments tend to have higher PLOS, while main arteries and roads such as The Palm and Sheikh Zayed Road have lower PLOS values. Since the complex measure is the result of the synthesis of various attributes, which either positively or negatively impact the final PLOS score, the scoring was broken down to its elements for deeper investigation (figure $3 \mathrm{~b}$ ). Variables whose scores were found to positively impact PLOS are sidewalk width (reaching up to $12 \mathrm{~m}$ ) and the presence of on-street parking, greenery or a buffer from vehicles (0-8m wide). In contrast, variables contributing to a lower PLOS are vehicle speed (ranging from $20 \mathrm{~km} / \mathrm{h}$ to $120 \mathrm{~km} / \mathrm{h}$ ), number of vehicular lanes (from I-6 lanes), traffic volume (varying from 50 to +5000 vehicles $/ H$ ) and the presence of a median on the road, which effectively extends the crossable distance from one side of the street to another.

The Space Syntax analysis revealed some key characteristics about the Dubai street network. The map (5a) reveals that a considerable share of Dubai's street network has a strong inherent capacity to support pedestrian movement. There is a clear gradual transition from local streets (highest) to main road arteries (lowest). Potential for pedestrian movement is significantly lower in the Deira area. As the subsequent choice maps clarify (5b), the Deira area street network is particularly suitable for longerdistance walking and cycling-reliant accessibility.

The pedestrian modelling of Dubai Business Bay, using CUBE software adapted to predict pedestrian flows, shows that potential pedestrian loads are highest along $\mathrm{Al}$ Mostaqbal Street and AI Khaleej AI Tejari I Street, with volumes double the average values, and about 6 times the segments with lowest anticipated volumes across the development.

Based on the comparative analysis of street space ratios and their impact on walkability, out of the 36 streets surveyed in Dubai's urban core, $80 \%$ were found to either be adequate for pedestrian activity or require low-cost interventions to reach an acceptable standard of walkability.

Junction spacing strongly correlates with levels of pedestrian activity along AI WasI Street. The Al-Satwa side has very frequent junctions with distances ranging from 130 meters to a maximum of 300 meters, but junctions on the Al-Suqeim side (mostly rightin/ right-out) are far sparser. Likewise, traffic lights with pedestrian crossings are also far more frequent in the northern segment, recurring every 280-500 meters, while the distance between signalized intersections on the Um Suqeim side of the street varies between 1.5 and 2 kilometres, making it difficult to efficiently navigate as a pedestrian. The study reveals a strong relationship between the two factors: land use structure and pedestrian crossings at junctions. If crossing opportunities are sparse - be it for large building blocks or limited intersections - the level of activity at the ground floor is diminished due to lack of opportunities to quickly arrive at these destinations. 
The Redemptive Potential of the Street.

\section{Three retrofitting strategies}

Based on the authors' reading and understanding of the streets of the city, this section provides some key strategies to adaptively retrofit Dubai's streets in order to combat the current pandemic situation without risking the loss of active modes of travel to private modes in the short run, and to enhance walkability of the city on the long run for all its users with diverse mobility needs.

Strategy 0 I: Narrowing vehicular lanes and promoting step-free pedestrian infrastructure to increase pedestrian safety, comfort and experiential quality Narrowing of vehicular lanes on streets is proposed where road space is excessive and could be repurposed as pedestrian space. Counterintuitively, empirical research suggests that wider vehicular lanes contribute to reduced driving safety beyond a limit; collision rates tend to follow a parabolic trend as vehicular lane widths increase (Karim 20I5). A potential application of this approach is the case of $2 \mathrm{~A}$ Street in Al Barsha area: the busy and lively street located near Mall of the Emirates and fronted by commercial activities of diverse natures. The street is essentially a wide two-lane road with onstreet parking space on either side and $3.8 \mathrm{~m}$-wide sidewalks. The research reveals that lane widths beyond $3.3-3.4 \mathrm{~m}$ contribute to higher crash rates, as do those less than $2.8 \mathrm{~m}$. Thus, by reducing car lanes from 3.4 meters wide to a more conservative width of 2.9, it becomes possible to extend one of the two sidewalks a significant amount without compromising the number of traffic lanes or driving safety (figure 15). The additional 2.2 meters gained help deliver a comfortable pedestrianized space that could be lined with parklets and other street-friendly public space features to soften the edge between pedestrian and road space, improve microclimates and offer recreational value. In that sense, the advantages of decreasing vehicular lane widths benefits both vehicular and pedestrian users. Further studies are required to ensure the viability of such retrofitting strategies under contextual traffic conditions.
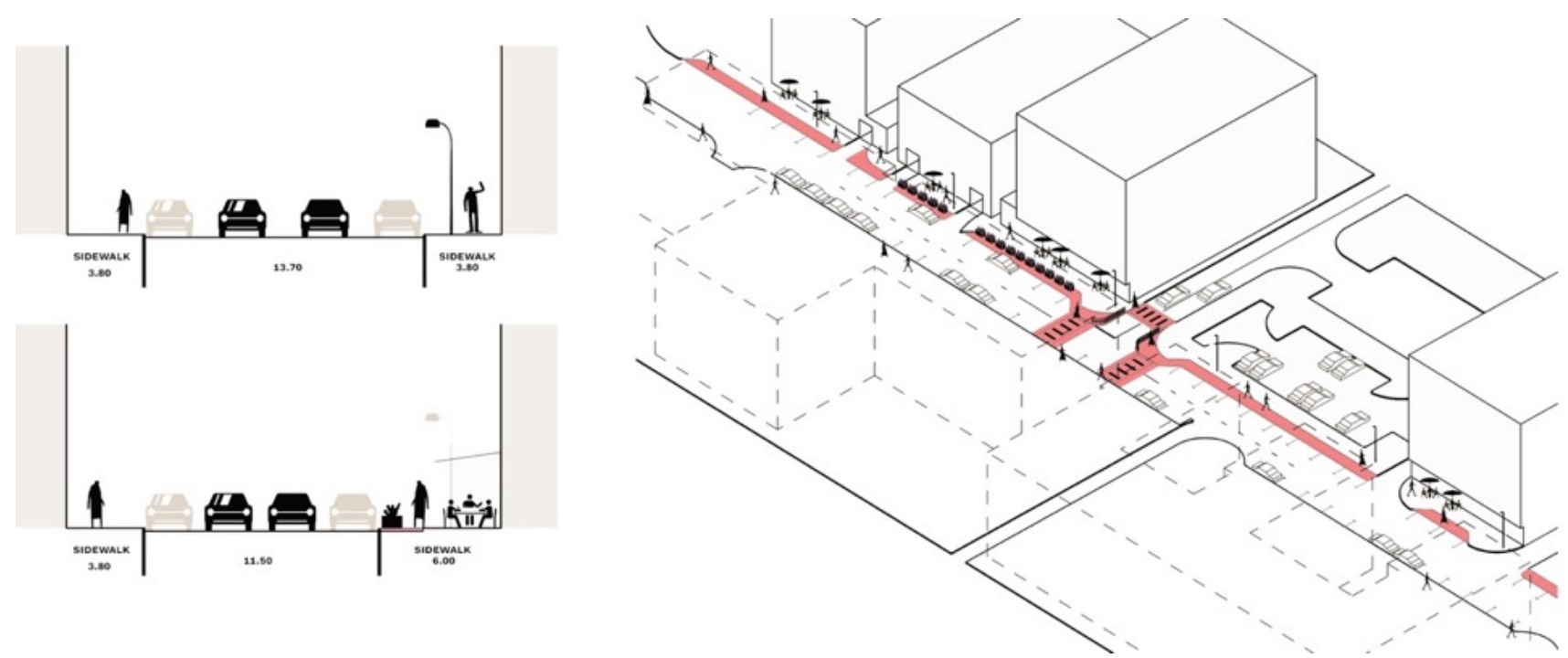

Figure 15. Retrofitting Strategy 0I Narrower vehicle lanes on 2A Street - property of Systematica srl 
Wheelchair users and users with reduced mobility conditions (such as elderly) can also benefit from a widened sidewalk for more comfortable movement and repeated rest zones. In a similar vein, Al-Sharta Street, which is a local access road located in one of the densest areas of Dubai, could benefit from some improvements to pedestrian infrastructure to support disabled and elderly users. Despite wide sidewalks, this street suffers from frequent curb cuts, which making movement particularly challenging for disabled users. Eliminating curb cuts at parking entry and exit points to promote a stepfree environment enhances walkability dramatically for these users. Where it is not possible to eliminate curb cuts, ramped edges are necessary to ensure continuous mobility for users of all physical abilities and mobility needs.

Strategy 02: Expanding the cycling network by adapting road space for cycle lanes Narrower vehicular lanes could also mean the possibility to extend the city's growing cycling network. As early as 2008, Dubai's Roads and Transport Authority (RTA) has been implementing a cycle masterplan set to deliver $900 \mathrm{~km}$ of cycle paths by 2020 (Alta Planning 2008). The linear expansion of the city has made it difficult to maintain pedestrian and cycling at the forefront of the mobility agenda and has made it easier to reach destinations by car. However, as the Space Syntax network analysis shows us, it is possible to create successful centralities efficiently organized around movements of up to $2500 \mathrm{~m}$ for cycling. Al Wasl Road is an ideal north-south axis with ample space to implement separated one-way cycle lanes on each side of the road, effectively connecting a large area of the city longitudinally (figure 16). Bicycle lanes have the capacity to connect infrastructure-segregated areas, such as in the context of Sheikh Zayed Road, and tend to contribute positively to cycling safety. Despite harsh weather conditions during the summer, Dubai enjoys moderate rain-free weather for 9 months of the year, which is ideal for cycling. Today, cities all around the world are closing off streets to cars and redirecting them to foot and cycling traffic. In Milan, the city added $35 \mathrm{~km}$ of bicycle lanes in the city centre using cost-effective techniques to facilitate movement during the coronavirus outbreak under its Strade Aperte (Open Streets) plan (Comune di Milano \& AMAT 2020). In New York, 100 miles (I60km) of streets are being repurposed in the wake of the pandemic to cater to pedestrians and cyclists (NYC Department of Transportation, 2020). With its recent 'Soft Mobility' scheme, Dubai could follow suit and embolden its cycling plans further in order to support the goal to reduce car reliance and attract more and more users to active modes of transport. Apart from increasing cycling safety, a dedicated cycling network (with separated cycle lanes) also increase perception of safety, which is commonly cited by women to be one of the leading concerns about cycling in cities, acting as barriers of use (Gorrini et al. 202I). Globally, women tend to cycle far less than men, and especially in countries where the overall cycling modal share is low (Goel et al. 202I). Thus, addressing women's concerns regarding safety is key to a gender-inclusive mobility system. 

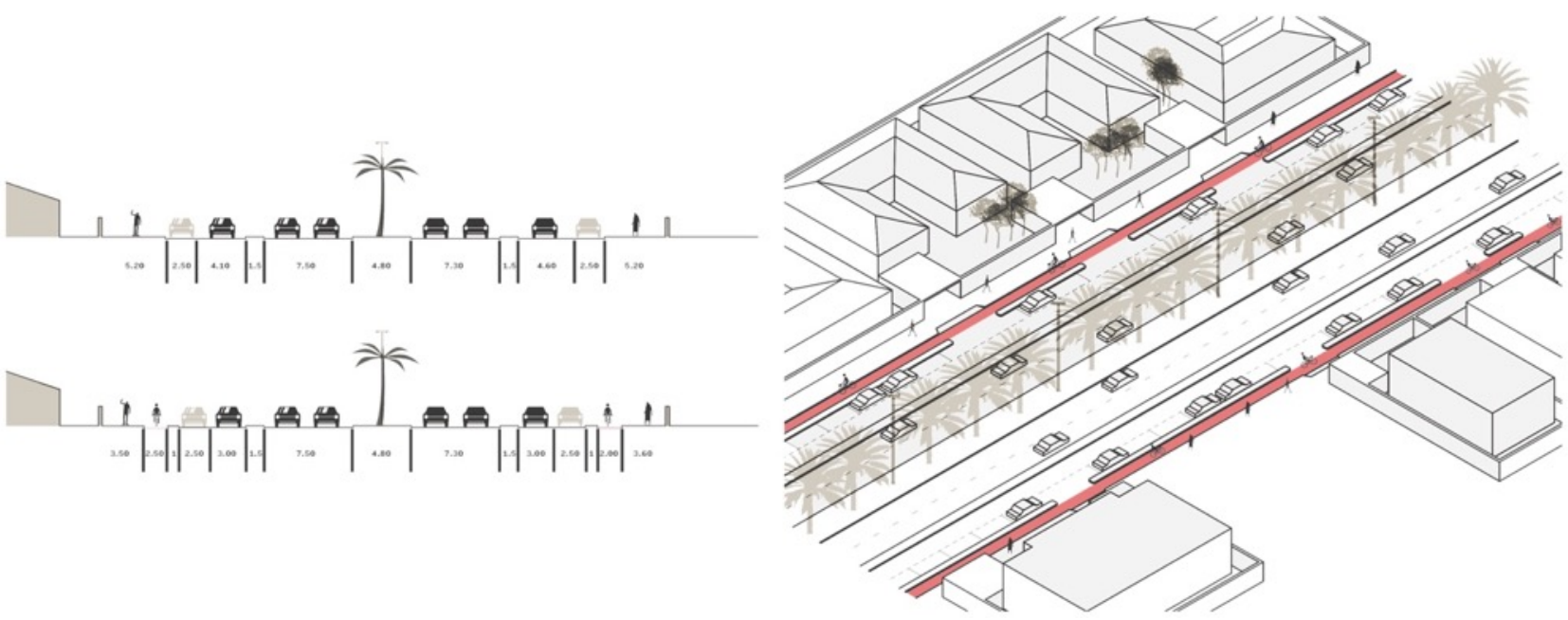

Figure 16 Retrofitting Strategy 02 Bicycle lanes on AI Wasl Road - property of Systematica srl

Strategy 03: Implementing traffic calming measures and encouraging pedestrian only spaces The final proposed strategy to deliver safe and comfortable pedestrian infrastructure focuses on the implementation of traffic calming measures. Dubai's new Soft Mobility Plan, the first phase of which began in the neighbourhoods of Karama, Mankhool and Al Qusais I earlier this year, focuses on the implementation of such measures to facilitate walking, cycling and micro-mobility (Government of Dubai RTA 2020). The RTA's comprehensive plan involves the addition of 2,000 cautionary signs; 77,000 square meters of adjusted pavements, 2 I built rest areas, 3 I 4 elevated pedestrian crossings and 66 speed-calming devices (Oommen 2020). Vehicle speed is one of the aspects having the most influence on the way a street is used and its character. Lower speeds encourage urban life and promote a high level of user safety, particularly for children. According to the World Health Organization (2018), road traffic injury is the leading cause of death among school-age children and adolescents globally. Moreover, more than half of road deaths are related to vulnerable users such as pedestrians and cyclers. The opportunity to reclaim streets for these vulnerable users greatly enhances child user safety and their inclusion in public space, as evidenced by the Freiburg Green City project in Germany, to take one example (Voce 2018).

Al-Fahidi Street is one of several streets in the bustling area of Bur Dubai that have a very active frontage and high pedestrian activity all day long. In a comprehensive study of vehicle speeds on all 36 streets under study, Al-Fahidi Street was found to be one of few where vehicle speed is already quite low - in the 'pedestrian street' category (figure 17). However, its design is oriented towards vehicular movement. To that end, the AlFahidi Street acts as an ideal prototype for the shared street model. By eliminating borders and shifting the balance between vehicle and pedestrian space, the 12-meterwide street adopts a flexible right-of-way: it becomes pedestrianized while allowing moderated vehicular flow to continue as normal, but giving off most of the street to pedestrians and cyclists (figure 18). The addition of road signs and bollards could ensure smooth interaction between different road users at different times, thereby increasing overall street safety. In London, the idea of 'low-traffic neighbourhoods' (LTNs) 
whereby streets are completely closed to non-local drivers is being rolled out in several areas; targeting II 4 neighbourhoods in total (Surico, 2020).
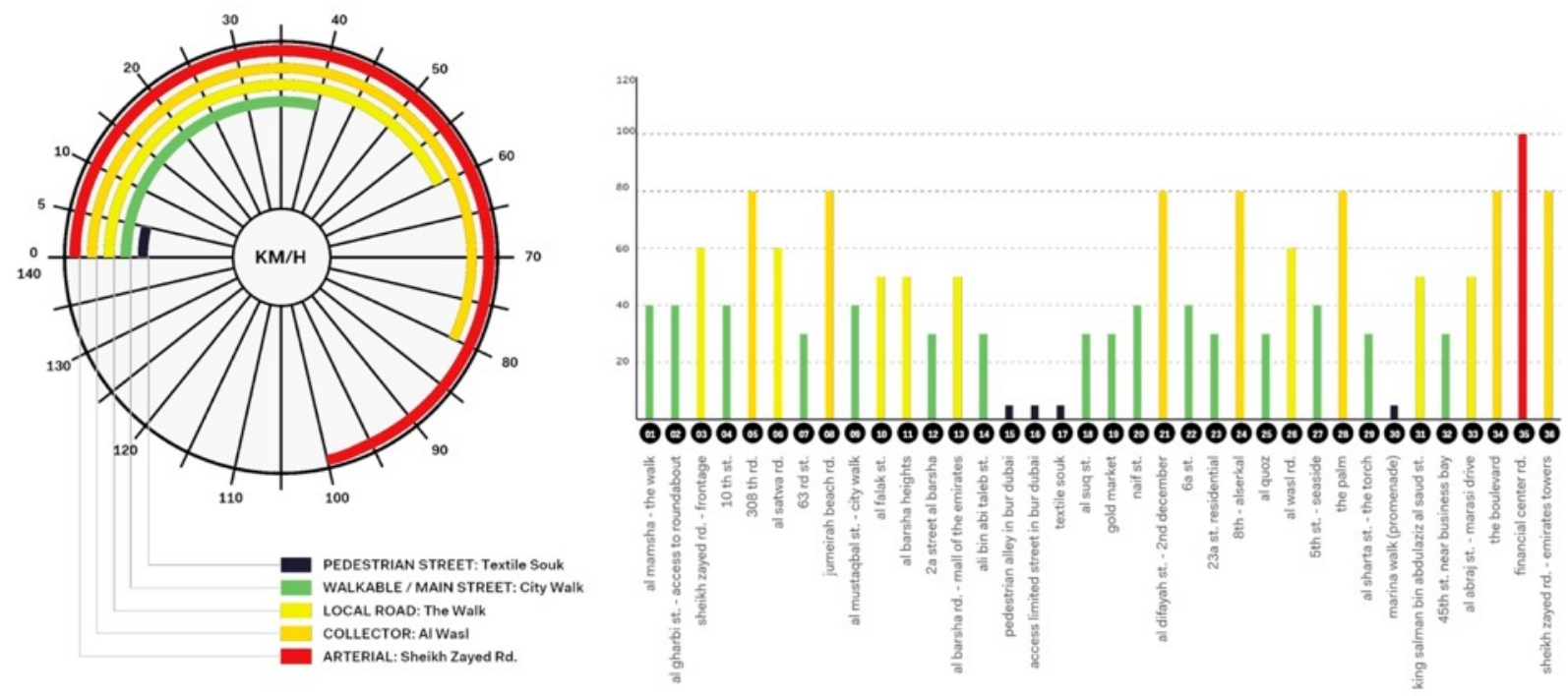

Figure 17 Vehicle speed on 36 selected streets in Dubai - property of Systematica srl
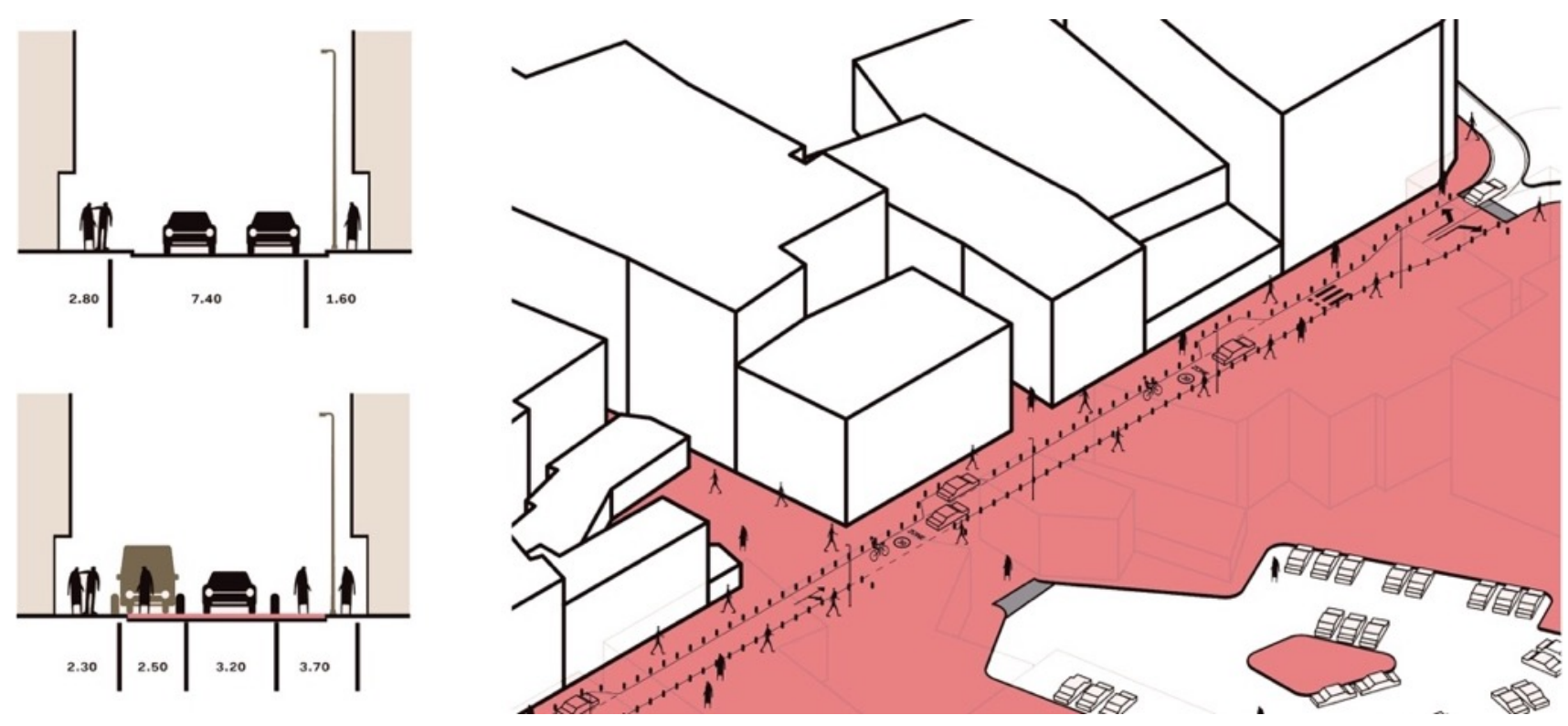

Figure 18 Retrofitting Strategy 03 Shared street model on Al-Fahidi Street - property of Systematica srl

\section{Conclusion}

This paper offers several starting points for adapting Dubai's streetscape to make it more walkable year-round. Starting from the Space Syntax network analysis, it is clear that the street network of Dubai - the blank canvas - creates a good foundational 
structure to support pedestrian connectivity. This is an important finding in itself because it limits issues of walkability to organizational aspects, eliminating the need to reconfigure streets, block sizes, etc. The paper discusses several ways in which the current organization of street space is disproportionately geared towards vehicular movement. Besides the well-known negative environmental impacts of car dominance on the urban environment, a mobility landscape that prioritizes the car tends to systemically discriminate against user groups that predominantly rely on public modes of transport, for whom alternative infrastructure is given less priority and is often underdeveloped. Examples of such users include low-income groups, immigrants, elderly and disabled users, Moreover, car dependency significantly affects the potential to promote active modes of transport in the city, such as walking and cycling, not in the least because of the added safety concerns caused by the omnipresence of these highspeed vehicles across the city. In that sense, the call to reclaim streets for pedestrians and vulnerable road users is intricately tied to the call for a more equitable, inclusive and balanced mobility system.

Analyses presented in this paper highlight the importance of relational space issues. The 36-street analysis of space distribution highlighted the importance of looking at the ratio between road space and sidewalk space, rather than sidewalk width alone, to determine the level of walkability of a street. In Dubai, sidewalk width is seldom the problem. As seen in the aforementioned study, sidewalk space is commonly generous with an average combined width of $8.5 \mathrm{~m}$ (more than $4 \mathrm{~m}$ per side). However, for the majority of the sample, sidewalk space is considerably offset by vehicular space (average ratio of 0.3), making wider streets less pedestrian-friendly. The scale of interventions required, however, is minimal for most of the streets in the survey sample.

Grid permeability is another area of concern when considering walkability. As demonstrated by the AI Wasl Street case study, the frequency of junctions and pedestrian crossing points can greatly influence the volume of pedestrian activity on different segments of the same street. Frequent intersections, pedestrian flow and active frontages tend to go hand in hand, as seen on the AI Satwa side of the street, where signalized intersections are 4 times more frequent than on the Um Suqqeim side, on average.

The role of co-dependent factors is strongly emphasized within the paper. We've seen examples from Dubai's streets where despite inefficient pedestrian infrastructure, pedestrian movement prevails due to productive dynamics of land use and density (Al Satwa Road). Measures of safety and comfort are even more pressing in these street segments where pedestrian flow is naturally higher. Conversely, we have seen areas where despite adequate sidewalk space, pedestrian flow is minimal due to low at-grade commercial activity and infrequent junctions (AI Wasl Road in Um Suqeim) or due to physical barriers such as the tram line (King Salman Bin Abdulaziz Al Saud Street). The paper thus holds that pedestrian infrastructure planning must be dealt with as a complex, multi-dimensional and integrated effort that reconciles various interdependent elements.

While street surveys and direct observation can offer critical insights about the functionality of pedestrian space at the experiential level, mobility metrics and mapping tools provide a complex reading of how various competing factors play out and an understanding of how each influences the whole. These tools therefore help to easily identify cluster areas for optimization. For example, the choice models using Space 
Syntax identified the Deira district as an area whose network renders it more suitable for travel by cycling. Likewise, pedestrian simulations of the Business Bay area helped us predict segments along internal routes with the highest perceived footfall. Applied to other projects and at wider scales, such data opens up space for more targeted plans and location-specific interventions to enhance walkability prospects.

The retrofitting strategies proposed in this paper focus specifically on those aspects with direct implications in the COVID- 19 era. Based on the collective reading and understanding of Dubai's street structure, these strategies are composed of targeted, measured actions perceived to have a major influence on the potentials of the city to support a modal shift to walking and other low-impact travel modes. Climate-controlled bus stops are a particular product of Dubai's unique relationship with the urban space dictated by its climatic conditions and cultural norms. The current situation presents an opportunity to rethink these relationships and devise new ways to articulate evolving and competing demands. Fit to measure, these concepts can be applied to other cities in the GCC region facing similar issues. As Rahm Emanuel, former Mayor of Chicago and former Chief of Staff for the Obama administration, asserts: "Never allow a good crisis go to waste. It's an opportunity to do the things you once thought were impossible" (Emanuel 2020). The current pandemic situation is an opportunity to tip the scales, to reorganize public space in a way that complements our long-term goals for the sustainable and equitable city, while making sure to navigate the current state of affairs without compromising public health or safety. Ultimately, the current situation is an opportunity to test the potentials of Dubai's massive street infrastructure to cater to a wider variety of users and transport modes; an opportunity to convert its 'leftover spaces' into core assets; and to incrementally direct the city towards a more inclusive and resilient future.

\section{References}

Al Sabbagh, N. (2019). Walkability in Dubai: Improving Thermal Comfort. Open University (United Kingdom).

Al Sabbagh, N., Yannas, S. and Cadima, P. (2016). Improving Pedestrian Thermal Sensation in Dubai. In PLEA 2016 Conference: 32nd International Conference on Passive and Low Energy Architecture: Cities, Buildings, People: Towards Regenerative Environments. Los Angeles, II-13 July 2016. Los Angeles: PLEA 2016.

Alsaka, I. (2019). Stitching the city: An Interview with lyad Alsaka. [online] Transform Transport. 3 June, https://research.systematica.net/interviews/stitching-the-city-focus-interview-withayad-alsakal

Alta Planning (2008). Dubai Bicycle Master Plan. [online] Alta Planning + Design, https://altaplanning.com/projects/dubai-bicycle-master-plan/.

Bata, A., Cenciarelli, O., Kinross, P., Penttinen, P., Plachouras, D., Semenza, J., Suetens, C. and Weist, K. (2020). Heating, ventilation and air-conditioning systems in the context of COVID-I9. [online] European Center for Disease Prevention and Control. ECDC, https://www.ecdc.europa.eu/sites/default/files/documents/Ventilation-in-the-context-ofCOVID-19.pdf.

Chidiac, T. (2020). “Double P!”, The Journal of Public Space, 5(I), pp. 247-262. doi: https://doi.org/|0.3289|/jps.v5il.II4I. 
The Redemptive Potential of the Street.

Comune di Milano (2020). Milano 2020 Strategia di adattamento: Documento aperto al contributo della città. [online] Comune di Milano, https://www.comune.milano.it/documents/20126/95930I0I/Milano+2020.++Strategia+di+a dattamento.pdf/c96c / 297-f8ad-5482-859c-90del d2b76cb? $\mathrm{t}=\mid 58772374950 \mathrm{I}$.

Comune di Milano and AMAT Agenzia Mobilità Ambiente Territorio (2020). Open Streets: Strategies, actions and tools for cycling and walking, ensuring distancing measures within the urban travel and towards a sustainable mobility, https://www.comune.milano.it/documents/20126/71 17896/Open+streets.pdf/d9be0547leb0-5abf-4 I0b-a8ca97945|36?t=|589|9574| |7|.

Dubai Roads and Transport Authority (2020). Soft Mobility Project to cover 3 Dubai areas. Government of Dubai [online] 25 January, https://www.rta.ae/wps/portal/rta/ae/home/news-and-media/allnews/NewsDetails/soft+mobility+project+to+cover+3+dubai+areas?lang=en

Dubai Statistics Center (2009). Total Lines' Length by Functional Classification and Carriage Way Type (In Km). [online] Government of Dubai, https://www.dsc.gov.ae/Report/DSC SYB 20II II I4.pdf.

Dubai Statistics Center (2019). Total Lines' Length by Functional Classification and Carriage Way Type* - Emirate of Dubai. [online] Government of Dubai, https://www.dsc.gov.ae/Report/DSC SYB 2019 II\%20\%2016.pdf.

Elessawy, F.M. (2017). The Boom: Population and Urban Growth of Dubai City. Horizons in Humanities and Social Sciences: An International Refereed Journal, 2(2).

Elsheshtawy, Y. (2008). Transitory Sites: Mapping Dubai's 'Forgotten' Urban Spaces. International Journal of Urban and Regional Research, 32(4), pp.968-988.

Emanuel, R. (2020). Opinion | Let's make sure this crisis doesn't go to waste. [online] Washington Post, 25 March, https://www.washingtonpost.com/opinions/2020/03/25/lets-make-sure-thiscrisis-doesnt-go-wastel.

Goel, R., Goodman, A., Aldred, R., Nakamura, R., Tatah, L., Garcia, L.M.T., Diomedi-Zapata, B., de Sa, T.H., Tiwari, G., de Nazelle, A. and Tainio, M. (202I). Cycling behaviour in 17 countries across 6 continents: levels of cycling, who cycles, for what purpose, and how far?. Transport Reviews, Pp.I-24.

Gorrini, A.; Choubassi, R.; Messa, F.; Saleh,W.; Ababio-Donkor, A.; Leva, M.C.; D’Arcy, L.; Fabbri, F.; Laniado, D.; Aragón, P. 202I, 'Unveiling Women's Needs and Expectations as Users of Bike Sharing Services: The H2020 DIAMOND Project'. Sustainability, I3(9), 524I. https://doi.org/10.3390/su13095241

Gunn, L. D., King, T.L., Mavoa, S., E.Lamb, K., Giles-Corti, B., Kavanagh, A. (2017). 'Identifying destination distances that support walking trips in local neighborhoods', Journal of Transport \& Health, 5, pI33-I4I.

Heil, E. (2020). As restaurants reopen, here's what you should know about air conditioning, air flow and the coronavirus. Washington Post. [online] 28 May, https:/www.washingtonpost.com/news/voraciously/wp/2020/05/28/as-restaurants-reopenheres-what-you-should-know-about-air-conditioning-air-flow-and-the-coronavirus/. 
Hodson, M. and Marvin, S. (20I6). The mutual construction of urban retrofit and scale: Governing ON, IN and WITH in Greater Manchester. Environment and Planning C: Politics and Space, 35(7), pp.II98-1217.

Honey-Rosés, J., Anguelovski, I., Bohigas, J., Chireh, V., Daher, C., Konijnendijk, C., Litt, J., Mawani, V., McCall, M., Orellana, A., Oscilowicz, E., Sánchez, U., Senbel, M., Tan, X., Villagomez, E., Zapata, O. and Nieuwenhuijsen, M. (2020). The Impact of COVID-19 on Public Space: A Review of the Emerging Questions. [online] ResearchGate, https://www.researchgate.net/publication/340819529 The Impact of_COVID19 on_Public_Space_A_Review_of the_Emerging_Questions.

Karim, D. M. (20I5). Narrower Lanes, Safer Streets. In Canadian Institute of Transportation Engineers (CITE) 2015 Conference. Regina, CA, 7-10 June, 2015.

Koronavirus Budapest (2020). Temporary bike lanes will help traffic during the pandemic. Koronavirus Budapest. [online] 06 April, https://koronavirus.budapest.hu/en/2020/04/06/temporary-bike-lanes-will-help-trafficduring-the-pandemicl

Lu, J., Gu, J., Li, K., Xu, C., Su, W., Lai, Z., Zhou, D., Yu, C., Xu, B. and Yang, Z. (2020). Early Release - COVID-19 Outbreak Associated with Air Conditioning in Restaurant, Guangzhou, China, 2020 - Emerging Infectious Diseases journal - CDC. Emerging Infectious Diseases, 26(7) [online] https://wwwnc.cdc.gov/eid/article/26/7/20-0764_article.

Matthews, R. (2020). Coronavirus: Is social distancing safe at less than two metres? [online] The National UAE, https://www.thenational.ae/uae/health/coronavirus-is-social-distancing-safeat-less-than-two-metres-1.1032692.

Montagne, C. (2012). Book Review: Elsheshtawy Y., 2010, Dubai: Behind an Urban Spectacle, London, Routledge, 294 p. Cybergeo: European Journal of Geography. [online], https://journals.openedition.org/cybergeo/25379.

Moreno, C. (2020). Urban life and proximity in the time of COVID-19. Translated from French by S. Houssiaux Paris: Editions de l'Observatoire.

Mushtaha, E., Al-Zwaylif, S., Merabti, F. and Hanane, I. (2018). Border vacuum: a study of walkability, liveability and vibrancy around Dubai mall station. Proceedings of the Institution of Civil Engineers - Urban Design and Planning, I7I(5), pp. I87-20I.

New York City Department of Transportation (2020). Open Streets, http://nyc.gov/html/dot//html/pedestrians/openstreets.shtml

Nikolopoulou, M. and Steemers, K. (2003). Thermal comfort and psychological adaptation as a guide for designing urban spaces. Energy and Buildings, [online] 35(I), pp.95-I0I, https://www.sciencedirect.com/science/article/pii/S037877880200084I.

Oommen, A. (2020). Phase I of RTA's "Soft Mobility" plan to complete by March 2020. [online] Construction Week Online Middle East, https://www.constructionweekonline.com/projects-and-tenders/262240-phase-I-of-rtassoft-mobility-plan-to-complete-by-march-2020.

Paris En Commun (2020). Ville du I/4h. [online] Le Programme d'Anne Hidalgo, https://annehidalgo2020.com/le-programme/. 
The Redemptive Potential of the Street.

City of Portland et al. (2012). 20-Minute Neighborhoods. [online] Portland Plan, https://www.portlandonline.com/portlandplan/index.cfm?a $=288098 \& c=52256$

Speck, J. (20I3). Walkable City: How Downtown Can Save America, One Step at a Time. New York City: Macmillan.

Surico, J. (2020). In Covid-1 9 Recovery, London Bets Big on Low Traffic. [online] Bloomberg CityLab, https://www.bloomberg.com/news/articles/2020-07-28/how-london-s-low-traffic-streetskeep-cars-at-bay?utm_campaign=socialfloworganic\&utm medium $=$ social\&utm_source $=$ facebook\&utm_content $=$ citylab\&fbclid $=I w A R 2$ q6MFIIIR2k3nb7Mh3pmdTzPXImkKBNIEDX3-rpZmKhG7oeH38jCHIfgw.

Systematica (2020). Milan Sidewalks Map. Transform Transport. [online] I May, https://research.systematica.net/research/milan-sidewalks-map/.

UAE Government Portal (2020). Guidelines Related to COVID-19. UAE Government [online], https://u.ae/en/information-and-services/justice-safety-and-the-law/handling-the-covid-19outbreak/guidelines-related-to-covid-19.

Victoria State Government (2020). 20-Minute Neighbourhoods. [online] Plan Melbourne 2017 2050, https://www.planning.vic.gov.au/policy-and-strategy/planning-formelbourne/planmelbourne/20-minute-neighbourhoods.

Voce, A. (2018). Cities Alive: Designing for Urban Childhoods. Children, Youth and Environments, 28(2), pp. 78-8I.

World Health Organization (20I8). Global status report on road safety 2018: summary (No. WHO/NMH/NVI/I8.20). World Health Organization.

World Health Organization (2020), Ciclovías Temporales, Bogotá, Colombia. WHO International [online] 28 October, https://www.who.int/news-room/featurestories/detail/ciclov\%C3\%ADas-temporales-bogotá-colombia. 